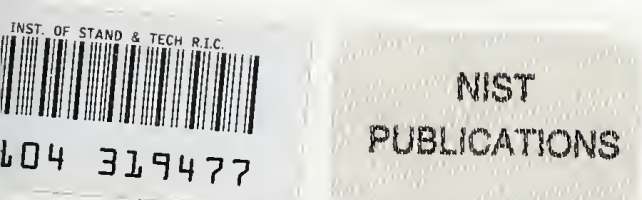

NISTIR 4489

\title{
Fire Growth Analysis of the Fire of March 20, 1990, Pulaski Building, 20 Massachusetts Avenue, N.W., Washington, DC
}

Harold E. Nelson

Building and Fire Research Laboratory

Gaithersburg, Maryland 20899

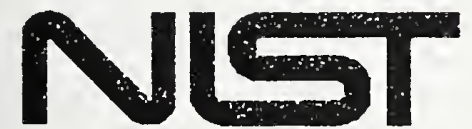

United States Department of Commerce inology Administration jonal Institute of Standards and Technology 



\section{Fire Growth Analysis of the Fire of March 20, 1990, Pulaski Building, 20 Massachusetts Avenue, N.W., Washington, DC}

\section{Harold E. Nelson}

Building and Fire Research Laboratory

National Institute of Standards and Technology

Gaithersburg, MD 20899

Issued June 1994

December 1990

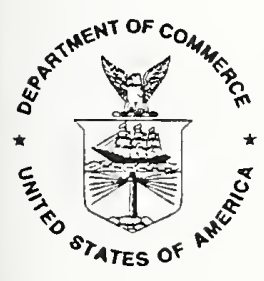

U.S. Department of Commerce

Ronald H. Brown, Secretary

Technology Administration

Mary L. Good, Under Secretary for Technology

National Institute of Standards and Technology

Arati Prabhakar, Director
Prepared for: U.S. Dept. of Army

Corps of Engineers 

TABLE OF CONTENTS

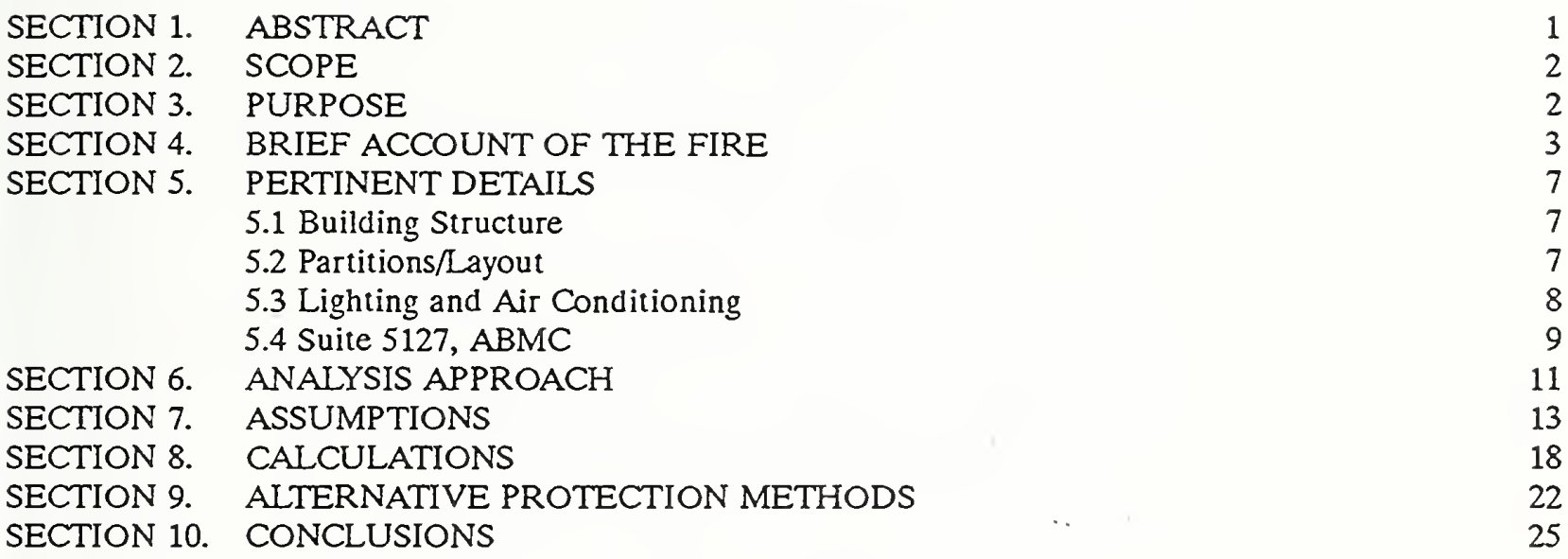

\section{LIST OF FIGURES}

Figure 1.

Figure 2.

Figure 3.

Figure 4.

Figure 5.

Figure 6.

Figure 7.

Figure 8.

Figure 9.

Figure 10.

Figure 11.

Figure 12.

Figure 13.

Figure 14.

Figure 15.

Figure 16.

Figure 17.

Figure 18.

Figure 19.

Figure 20.

Figure 21.

Figure 22.

Figure 23.

Figure 24.

Figure 25.

5TH FLOOR, 29 MASSACHUSETTS AVE. NW, WASHINGTON, DC

SUITE 5127 - ARMY BATTLEFIELD MONUMENTS COMMISSION 26

FAN ROOM ELEVATION (TYPICAL) 27

CONFERENCE ROOM ON MARCH 23, $1990 \quad 27$

LIKELY ARRANGEMENT OF PODIUM 28

EST. FLAME EXTENSION 28

ESTIMATED FIRE SIZE

SMOKE TEMPERATURE 29

SMOKE LEVEL $\quad 30$

OXYGEN IN SMOKE

CO IN SMOKE $\quad 31$

EXT. VISION IN SMK

ELEVATION - CONFERENCE ROOM AREA - ABOUT 11:22 AM 32

ACTIVITIES IN ABMC SUITE - ABOUT 11:15 TO 11:22 AM 32

ELEVATION - CONFERENCE ROOM AREA - ABOUT 11:23 AM 33

ACTIVITIES IN ABMC SUITE - ABOUT 11:22 TO 11:23 AM

ELEVATION - CONFERENCE ROOM AREA - ABOUT 11:24 AM

ACTIVITIES IN ABMC SUITE - ABOUT 11:23 TO 11:24 AM

ELEVATION - CONFERENCE ROOM AREA - ABOUT 11:25 AM

ACTIVITIES IN ABMC SUITE - ABOUT 11:24 TO 11:25 AM

ELEVATION - CONFERENCE ROOM AREA - ABOUT 11:26 AM 36

ACTIVITIES IN ABMC SUITE - ABOUT 11:25 TO 11:27 AM 36

ELEVATION - CONFERENCE ROOM AREA - ABOUT 11:27 AM 37

ACTIVITIES IN ABMC SUITE ABOUT 11:27+ AM 37

TIME LINE OF EVENTS $\quad 38$

APPENDICES

APPENDIX A. Printout of results of FIRE SIMULATOR run for Conference Room 39

APPENDIX B. Printout of results of FIRE SIMULATOR run for ABMC suite. 41

APPENDIX C. Printout of results of FIRE SIMULATOR run for 5th floor.

APPENDIX D. Printout of results of FIRE SIMULATOR runs used to establish

the response of sprinklers and smoke detectors. 

Fire Growth Analysis of the Fire of March 23, 1990

Pulaski Building, 20 Massachusetts Avenue, N.W., Washington, DC

Harold E. Nelson

Center for Fire Research

National Institute of Standards \& Technology

Gaithersburg, MD 20899

\section{ABSTRACT}

An analysis of an office building fire was made using fire modeling techniques. The data to conduct the analysis was obtained through on-site inspection and interviews. The analysis describes a rapid fire developing in easily ignited boxing materials that flashed over in about six minutes from flame initiation, causing failure of the ceiling system, venting of fire products in the plenum system above the ceiling, and rapid filling of the entire flow area with smoke. The report suggests a likely source of ignition and provides analysis of the impact that several fire protection systems would have had were they present at the time of this fire. 


\section{SCOPE}

This report addresses the growth and spread of the fire of March 23, 1990, in suite 5127 of the Pulaski Building, 20 Massachusetts Ave. N.W. Washington, D.C. This reconstruction analysis was conducted at the request of the Safety \& Occupational Health Office, Corps of Engineers (COE), U.S. Department of the Army. The suite of rooms involved in the fire was occupied by the Army Battlefield Monuments Commission (ABMC). Figure 1 locate the $A B M C$ suite on the plan of the 5th floor of this building.

\section{PURPOSE}

The overall purpose of this report is to assist the COE in obtaining an accurate understanding of the events of the fire as an input to their decision making. An additional intent is to demonstrate the value of the application of a scientifically sound fire protection engineering tool in fire safety analysis. The specific purpose of the reconstruction analysis contained in this report is to identify the course of events in terms of what was or was not physically possible when considered in light of the laws of science applicable to fire. To do this a two step process was used:

1. Those specific events and conditions reasonably identified or derived from the physical evidence at the fire site, the recollections of witnesses, and the records of the District of Columbia Fire Department were established. 
2. Application of the applicable laws of science was then used to estimate the rate of fire growth and resulting environmental situation that most nearly fit the established events and conditions. Fire modeling techniques were used to implement this phase.

This led to the establishment of a most likely course of events as is described in the next section of this report. ${ }^{1}$ This is followed by. several sections detailing the technical aspects of the analysis and a final section providing the conclusions drawn.

\section{BRIEF ACCOUNT OF THE FIRE}

At approximately 11:24 to 11:25 a.m., a ABMC staff member noted smoke emitting from the open door of the unoccupied Audio/Visual (A/V) room. (See Figure 2 for the layout of the $A B M C$ suite and the normal workstations of the ABMC staff.) He called out a warning.

${ }^{1}$ This approach to the application of fire science and the use of fire modeling as a tool in fire incident reconstruction has emerged during recent years as an important tool in fire incident investigation. Two examples of the application of these techniques are contained in the reports:

"An Engineering Analysis of the Early Stages of Fire Development - The Fire at the Dupont Plaza Hotel and Casino - December 31, 1986" Report NBSIR 87-3560, National Institute of Standards and Technology, Gaithersburg, MD, 1987.

"An Engineering View of the Fire of May 4, 1988 in the First Interstate Bank Building, Los Angles, California" Report NISTIR 89-4061, National Institute of Standards and Technology, Gaithersburg, MD, 1989 
Others responded and quickly identified the Conference Room adjacent to the $A / V$ room as the room containing the fire. The Conference Room at that time was being used for the storage of $A B M C$ publications and other materials. The likely, but not certain, cause of the fire was the shorting and subsequent flaming of the.cord for the lamp on the Conference Room podium, resulting in the ignition of corrugated boxes containing cardboard mailing tubes.

As is characteristic of fires involving boxes of corrugated paper board construction, the fire developed at a very rapid rate. By about 11:26 a.m., the fire in the Conference Room flashed over ${ }^{2}$. With this occurrence, large quantities of hot black smoke flowed into the rest of the suite. It is likely that the initial post flashover flow of smoke contained potentially lethal concentrations of carbon monoxide. Very soon after flashover, however, the suspended ceiling in the Conference Room started to fail, as this ceiling opened up, the smoke and heat vented into the open plenum space above the ceiling. This changed the nature of the fire from one confined to the suite to one spreading high temperature

\footnotetext{
${ }^{2}$ Flashover is a phenomena that occurs in most major building fires. In the initial (pre-flashover) stages, fire development is controlled entirely by the availability of combustible materials, the ease of fire spread and subsequent burning rate of the involved fuel. As the fire develops, however, the hot smoke and fire gasses accumulating at the ceiling, heating all of the yet un-ignited materials in the room. The hot ceiling gases also radiate energy onto the burning fuel causing it to burn faster. This increased burning rate often results in a throttling of the available air supply, causing some of the fuel gases released by the combustible material to collect, unburned, in the smoke layer. The smoke normally blackens at that time. When this combination of events reaches a temperature of about 1000 to 1100 degrees $F$ (550 to 600 degrees $C$ ) the radiant heat from the hot gas layer will quickly ignite all of the exposed combustible material. Frequently any combustible gases accumulated in the smoke will find air and burn out at about the same time. When this rapid ignition of exposed combustible material and/or combustible gases in the smoke layer occurs, the fire often violently erupts from the room of origin spouting llame, hot fuel laden gases, and toxic smoke into adjacent spaces. This transition is called flashover.
} 
combustion products through the plenum space and from that space to other portions of the fifth floor. To some extent, smoke also spread to other floors (though the make-up air shafts for the HVAC fans).

The ceiling failure slowed the deterioration of conditions in the ABMC suite, possibly avoiding serious harm to the last person(s) to leave the suite. The failure of the ceiling exposed the wiring of the fire alarm system to direct flame impact, causing it to fail. The fire alarm system failed just moments after a fire alarm box had been pulled by evacuees from the $A B M C$ and adjacent suites. Soon thereafter, portions of the building lighting circuit also failed. The flame entered the plenum space, thus limiting actual burning to the contents of the Conference Room and adjacent spaces. As the flame and other fire effects vented into the plenum, the lighting fixtures and other utilities in the plenum were subjected to flame (nearest the fire source) and hot gases.

From this point on, the fire effects spread through the plenum and entered the office spaces under the ceiling through the ceiling vents and other openings and leakage cracks in the ceiling system. Following this route, the fire involved the entire floor space, filling it with smoke from the ceiling void down; the areas nearest the source being the hottest. Small quantities of polychorinated biphenyls (PCB) were released from condensers in the florescent lamp ballasts in ceiling fixtures located close enough to the actual burn area to receive sufficient heat to rupture the condenser elements. This contaminated smoke left 
heavy deposits over most of the 5th floor and lesser but significant deposits on the 4 th and 6th floors.

As the fire progressed, the venting of the flame into the plenum void protected most of the other spaces in and near the ABMC suite from ignition. The lighter fuel elements in the Conference Room (e.g., the mailing tube boxes and other loosely packed materials and exposed surfaces of $\mathrm{e}$ errugated boxes) determined the initial rapid development to flashover but were quickly consumed. The exact duration of such burning is impossible to establish but was probably over in the range of about five minutes following flashover. Under normal post flashover conditions, it would be expected that the intense conditions within the room would have continued the fire at nearly the same intensity. In this fire, however, there were two mitigating circumstances that are felt to have resulted in a fire that after having established itself, died without consuming more than a small portion of the total fuel present in the Conference Room. First the failure of the ceiling vented a significant portion of the flame into the plenum space. This raised the flame from the remaining combustibles into the plenum space. The shielding provided by the remaining portions of the ceiling greatly reduced the amount of energy feedback to the burning combustibles. Also, as the fire continued, it progressively reduced the oxygen available for combustion. As the oxygen depleted smoke layer descended to the level of the fuel, it depressed the burning rate. As a result, about 80 to 90 percent of the fuel content of the materials in the Conference Room remained unburned after the fire. The fire was essentially out when the responding firefighters reached the area of the $A B M C$ space. The time of the arrival of the first 
firefighter at the $\mathrm{ABMC}$ space cannot be exactly established but is estimated at between $11: 35$ and $11: 40$.

Fortunately, no lives were lost; however, significant contents and partitioning damage occurred through approximately 2000 square feet of the 5 th floor with contaminated smoke deposits requiring temporary abandonment and extensive decontamination of the entire 4 th, 5 th, and 6th floors.

\section{PERTINENT DETAILS}

\subsection{Building Structure}

The building is of flat slab reinforced concrete construction. There is a suspended gypsum panel ceiling in an exposed steel grid system. The ceiling system is not fire rated.

\subsection{Partitions/Layout}

All partitions, except those for shafts, restrooms, and similar special purpose spaces, are terminated at the ceiling. A main loop corridor with a cross connection at the elevator lobby is formed with ceiling-high, gypsum-board-on-steel-stud partitions. This results in an undivided space about 18 inches deep above the ceiling extending over most of the floor area. This space is used as a return air plenum. 
The ABMC occupied a suite of approximately 2500 square feet in the south west corner of the 5th floor. The suite ran in an east-west direction with a door near each end. Each of these doors opened from the building circulation corridor into a general circulation space. There was an internal corridor running in the east-west direction. Offices were located on the south (exterior) side with a conference room, a related $A / V$ room, and several other service rooms on the north (interior) side.

\subsection{Lighting and Air Conditioning}

Lighting throughout the building is provided by four tube fluorescent fixtures mounted in the ceiling grid. Each light fixture has two Underwriters Laboratories (UL) labeled ballasts of the thermally protected type. In many of the light fixtures, two of the four fluorescent tubes have been removed.

The building lighting fixtures also serve as air supply and air return fixtures. Each 4th to 5 th light fixture is connected to an air supply duct fed from a fan room serving one half the floor. There are two fan rooms on each floor. The vent openings in the other fixtures provide the air transfer paths from the occupied portion of the building beneath the ceiling to the return air plenum space above it. Each floor is an independent air handling system. There is no designed passage of air from floor to floor. 
There are no return air ducts in the general air conditioning system in this building. The arrangement of the air handling fans is shown in Figure 3. Air is drawn into the each fan from the air in the fan room. The fan room partitions terminate at the ceiling, providing free flow of return air from the ceiling plenum to the fan room.

Return air is drawn by the fans from the occupied space through those lighting fixtures that are not connected to supply ducts, through the plenum space, into thefan room. The air is then pulled, by the fan suction, into the fan feed opening of one of the fans in the fan room and recirculated (after conditioning) through those lighting fixtures that are connected to supply ducts. Make-up air is also drawn into the fan room by fan suction from a vertical shaft connected to the outside. In addition to the designed openings between the make up air shafts and the fan rooms, additional openings have been created by breaking out portions of the concrete block separation between the shaft and the fan room. Such an additional opening was found in each fan room inspected during the investigation. There are no fire or smoke dampers in the system.

\subsection{Suite 5127. ABMC}

During the several weeks prior to the fire, the $A B M C$ was required to remove its storage of bulk quantities of pamphlets, lithographs, and other material from a space in the basement of the building. The material was relocated to suite 5127 . Also, in preparation for expected laying of carpet in the east half of the suite, the supplies normally stored in the 
storage area and the $A / V$ room were relocated to space in the west half of the suite. In general, every available space in the west portion of the suite was used to accommodate these materials. The Conference Room received the bulk of the material. Figure 4 is a plan view of the Conference Room showing the arrangement of the storage in it. Based on the data supplied and the average weight of paper, there was about 10,000 pounds of combustible material in the Conference Room. Most of the combustible material consisted of publications and lithographic photos either tied in bundles or contained in ecragated cardboard boxes. Most important to the principal suspected fire scenario, corrugated board cartons containing cardboard mailing tubes were stacked to a height of about 5 feet in the north east portion of the room.

As of this date, no plans, photos, or clear recollections of the arrangement of the lighting fixtures in the Conference Room have been obtained.

There was a plastic rear projection screen mounted in the wall between the $A / V$ room and the Conference Room. It is understood that this screen was covered by a draw curtain of unidentified material. The equipment for making presentations was located in the $\mathrm{A} / \mathrm{V}$ room and viewed from the Conference Room.

The Conference Room contained a podium (See Figure 5.) This podium had controls to remotely operate a slide projector located in the $\mathrm{A} / \mathrm{V}$ room. It also had a podium light. The light is believed to have been a small 110 volt low wattage lamp with current supplied 
by a simple lamp cord. The lamp cord and the control wires passed through a small diameter (estimated at about 1 inch diameter) hole cut in the partition separating the $A / V$ room from the Conference Room. It is understood that this arrangement was made some years ago and at the time it was done, the portion of the cord in the pass.through hole had been wrapped with friction tape.

During the re-arrangement of the Conference.Roomst other locations, this podium was moved without disconnection of the cord arrangement. The podium was moved a few feet from a position near the north east corner to a location on the east wall near the north edge of the rear projection screen.

It is not known whether the movement of this podium along with the arrangement of the storage placed any stress on the lamp cord or otherwise caused it to be pinched or drawn against a sharp edge. Any remains that existed were disposed of with the fire debris prior to the start of this analysis.

\section{ANALYSIS APPROACH}

The Center for Fire Research was called in to this investigation several weeks after the incident. When the CFR representatives arrived, the contents of the Conference Room and most of the contents of the $\mathrm{A} / \mathrm{V}$ room had been removed and were either unavailable or 
unidentifiable in a trash dumpster. Shoring had been installed throughout these rooms. The remainder of the suite was close to the condition found at the end of the fire. Several video and photographs were available that showed some views of the Conference Room area prior to removal of the damaged contents. The information available from these, while helpful, was limited.

The author, jointly with representatives of the Corps of. Engineers, interviewed ABMC staff members that were involved in the fire or events related to it. Data was obtained from the District of Columbia Fire Department and from Mr. Joseph O'Hagan, the first Federal fire protection professional to investigate the site after the fire.

The information obtained gave a generally sufficient outline of the sequence of conditions faced by the ABMC staff, the response of the building system (fire alarm and electric lighting), the building arrangement, and the fuel load conditions in the Conference Room.

The physical arrangements pertinent to the fire are graphically depicted in figures 1 through 5. The analytical results of the engineering calculations are plotted in figures 6 though 12 and graphically depicted at one minute intervals in figures $13,15,17,19,21$, and 23 . The actual variables and results of the principal calculations involved are contained in appendices A through $\mathrm{D}$. The principle analysis tools used were the programs and procedures included 
in FPETOOL. ${ }^{3}$ Figures $14,16,18,20,22$, and 24 track the activities of the ABMC staff up to the time the $\mathrm{ABMC}$ suite was evacuated (approximately 11:27 a.m.) Data for these figures was obtained from interviews of the staff members involved. Figure 25 combines important events of fire development, staff, and fire department activities into a single time line.

\section{ASSUMPTIONS}

In any fire reconstruction analysis, it is necessary to make rational assumptions to fill information gaps and resolve apparent inconsistencies in the data and testimony available. While the basic character of this fire was evident, a number of assumptions were required. Each assumption necessarily impacts on the degree of confidence in the results. The most significant assumptions include:

1. The assumed initial fuel package was cartons of mailing tubes in the north east corner of the Conference Room.

The only persons to actually see conditions in the Conference Room were persons B (a senior secretary) and E (a senior military officer.) While their recollections are similar, neither recalls seeing the other in the vicinity of the Conference Room. While both must

${ }^{3}$ FPETOOL is a computerized collection of convenient fire protection engineering equations and models designed for fire hazard and fire investigation analysis. The computer program FPETOOL is available through the Center for Fire Rescarch Computer Bulletin Board and is documented in the NIST report NISTIR 4380 "FPETOOL - Fire Protection Engineering Tools for Hazard Estimation" 
have been near the door to the Conference Room within a time period of less than one minute, there is no clear way to determine which observed the fire first. More important is the fact that both of these individuals saw flame at the ceiling, while the most logical scenario for this fire places the base of the fire near the floor.

Person E stepped from his office almost directly across the internal ABMC corridor from the open west door of the Conference Room and saw "ropes" in a partially separated sheet from the ceiling. The flame seemed to stop short of the table top and to be about 1 to 2 feet wide. Person E placed the flames he observed near the center line of the Conference Room in the east quarter of the room but not against the east wall. There was some initial consideration that the source of this flame might have been from an overheated fluorescent lamp ballast and person $E$ might have seen the initiation of the fire. However, person $\mathrm{E}$ did not become involved in the fire sequence until after person $G$ and several others had observed smoke issuing from the $A / V$ room. Such smoke build-up would have necessitated a fire of larger size than possible from the total combustible fuel in a light ballast. More likely, person $\mathrm{E}$ saw the burning of the plastic lens for a fluorescent fixture, hanging from one end and on fire. The level of confidence in this possibility could be better analyzed if the actual arrangement of the ceiling lighting fixtures could be established. Even so, for this analysis, it is assumed that person $\mathrm{E}$ saw a flaming lens. The specific of what was burning is not individually important. However, it is concluded that at the time described by person $\mathrm{E}$, the fire was in a sufficiently advanced stage of burning for 
flame extension to ignite a fuel at the ceiling. ${ }^{4}$ Figure 6 is a graph of the estimated flame extension against time.

Person $\mathrm{B}$ also reported seeing flame flowing downward from the ceiling. She did not actually reach the door to the Conference Room (See figure 20). While she stated that she saw the east wall of the Conference Room, the viewing angle from the position she recalled she took would reveal only the north wall (the approximate location of her viewing position is indicated on figure 20 by the tip of the arrow extending from her workstation towards the Conference room.) Even if she had approached closer to the Conference Room, only the north wall would be visible unless she had actually stood at the door of the Conference Room. She was firm in her recollection that she did not actually go to the Conference Room door. On this basis, this analysis assumes that she saw flame extension from the actual fire source and the downward movement of a flame vortex extending from the source along the junction of the ceiling and the wall.

\footnotetext{
${ }^{4}$ When the results of the investigation were discussed with $A B M C$ staff members, person $E$ felt that the scenario considered as most likely (i.e., the one presented in this report) was at odds with his observations. The scenario estimates the person E probably first saw the fire at about 11:24 to 11:25 a.m. This would place the fire size as between 1 and 2 megawatts with flame extension estimated at 9 to 11 feet. Such would produce a flame sufficient to ignite the fluorescent fixture lens and to that extent fits person E's observation. Person $\mathrm{E}$, however, believes that he had a clear view and the only flame he saw was extending downward from the ceiling. Such a fire would be expected to be in the range of 100 to 200 kilowatts (i.e., 0.1 to 0.2 megawatts). When person E looked again (estimated as within one minute of his first observation), the smoke had changed to a black obscuring condition and was highly turbulent (described as boiling by person E). The fire growth rate necessary to raise the conditions from a localized fire as recalled by person $E$ at his first look to the violent conditions observed at his (about 1 minute) later would require a growth rate beyond that expected for the types of combustible materials present. The assumption of a 1 to 2 -megawatt fire at the time person E first observed the flames from the ceiling requires the corollary assumption that the actual combustion at that time was significantly more than that indicated by those flames observed by person $\mathrm{E}$.
} 
2. The cause of the failure of the fire alarm system was flame impingement on a section of fire alarm cable in the ceiling void over the Conference Room.

The structural fire resistance in this building is provided by the reinforced concrete construction. The suspended ceiling plays no part in this function. The ceiling system is supported by an exposed metal grid and does not have a. specific fire resistance. The portion of the ceiling system in and around the Conference Room failed during the fire. It is believed that this occurred soon after the Conference Room flashed over. It is believed that the first significant failure occurred at about 11:27 a.m. At that time, the fire alarm was heard but, as reported by $A B M C$ staff members, sounded for only a few seconds. A fire alarm circuit was located in the partition between the Conference Room and the building circulating corridor. A similar installation was examined on the 7th floor. At that location, the alarm circuit was partially in conduit and partially exposed. The exposed portion being above the ceiling line. For this analysis it is assumed that the ceiling in the Conference Room failed at approximately 11:27 a.m. and that the failure was extensive. This is assumed to have allowed flame impingement on the fire alarm wiring. This conclusion is important in the analysis. The ceiling failure had a major impact on fire development as discussed in the preceding section on the story of the fire.

3. The doors to the ABMC suite were closed at the start of the fire but opened by escaping staff members about 11:26 a.m. 
The opening of the ABMC suite doors by the staff as they evacuated had an effect on the smoke accumulation within the suite. The exact time can only be estimated. While it is not likely that both were opened at the same time, this analysis for lack of more concise data assumes that both doors were opened at 11:26 a.m. The assumption that the doors were first closed and then opened impacts the rate of smoke filling of the $A B M C$ suite.

4. The initial fire growthwas asapid and exponential in rate of increasing intensity.

The use of the procedures in FPETOOL for analysis of this fire requires an estimate of the rate of energy release produced by the fire source up to the time that flashover occurs. Every different ignition of any fuel produces at least a sightly different burning history. Experience has shown, however, that a reasonable approximation can be made by assuming that in the initial stage the burning rate increases exponentially with the exponent increasing with time. After the fire reaches a more steady rate of burning per unit surface area, the rate can be estimated as increasing with the square of time. FPETOOL includes routines for making such estimates. There is a reasonable database on the burning rates of materials in corrugated containers. The burning rate is consistently fast. Several variations were tried. That which FPETOOL indicated as producing fire conditions most nearly consistent with the conditions reported by the witness was used. The specific equations and resulting rate of 
heat release history used are shown in Figure 7. The rates used are approximately those most expected from corrugated boxes ${ }^{5}$

5. The initial stages of burning were clean with an excess of available combustion air. As the fire developed, this changed to a smokey fuel rich fire.

The fact that persons B and..Ecouldasee details of the flame briefly before flashover is considered indicative of very clean burning up to a point close to flashover. This is felt to be a reasonable assumption since the prime fuel consisted of paper products and there was adequate air for complete combustion in this stage of burning. As the fire approached flashover, the rate of fuel gas driven from the combustible material in the room started to exceed the amount of combustion supportable by air drawn in through the Conference Room door. With this, the efficiency of combustion started to reduce, resulting in a rapid darkening of the smoke.

\section{CALCULATIONS}

FPETOOL contains an integrated calculating procedure for estimating conditions in a room on fire. This procedure is titled FIRE SIMULATOR. FIRE SIMULATOR estimates the environmental conditions, temperature, depth of smoke, thickness of smoke, carbon

5 A listing of the rates of heat release to be cxpccted from various fuels, including corrugated boxes is contained in NFPA Standard 204M, Guide for Smoke and Heat Venting published by the National Fire Protection Association. 
monoxide in the smoke, and other environmental changes causêd by a fire in the room being evaluated. It also estimates the amount of energy vented through openings in the room.

The calculations were divided into three stages individually covering: (1) the development of conditions in the Conference Room; (2) conditions through the rest of the ABMC suite; and (3) conditions throughout the 5th floor. Until the ceiling failed at about 11:27, the conditions in the ABMCasurite resulted from smoke, gases, and vaporized fuel products emitted from the open door of the Conference Room. During this same period, a limited amount of these same products vented into the plenum space filling that void. Once the void was filled, smoke vented through light fixtures into spaces outside the $A B M C$ suite. At the time of the Conference Room ceiling failure, the smoke had descended to about one to two feet below the ceiling line. When the ceiling failed, the total force of the fire was directed into the plenum space and the smoke level in the Conference Room and the $A B M C$ suite started to rise. Shortly after that, the smoke vented down through the ceiling vents (vents in light fixtures and other openings) and reached the level of the smoke in the Conference Room and the ABMC suite. From this point on the smoke level is estimated as being at the same depth across the entire 5th floor.

Initially, FIRE SIMULATOR was used to appraise the development of conditions in the Conference Room. A number of runs were made in order to estimate the clock time of fire initiation. This was done by assuming that flashover occurred at approximately 11:26 a.m. While this is an arbitrary assumption, it fits closely with the recollections of the persons 
present and the timing of the alarm received by the fire departimenit: 'FIRE SIMULATOR estimates that given the condition of the room and a fire releasing an energy at the rate plotted in Figure 7, that flashover would occur at about 268 seconds into the fire. This would place the moment of open flaming ignition at approximately 11:21:30 a.m. Such an estimate is, of course, overly precise as the energy release rate of the fire may have taken a somewhat different course than that predicted by Figure 7. It is reasonable, however, to assume that the first appearance of flame was in that time period. It is recognized that 11:21:30 a.m. is uncertain. It is, however, used throughout this analysis as the moment of flame initiation.

In addition, FIRE SIMULATOR was instructed to halt approximately one minute after flashover (330 seconds) in the simulation (i.e., 11:27 a.m). At that time, the program was instructed to simulate failure of the entire ceiling system. While it is known that grid type ceiling systems can fail quite suddenly, it is probable that it was not instantaneous as modeled. The instant total failure simulation was used, however, for lack of a better approximation.

The combination of energy and potential fuel in the vented gases from the door were used as the input fire to make initial estimates of the change and conditions throughout the portions of the $A B M C$ suite outside of the Conference Room. 
After ceiling failure, it was assumed that all the portions of the entire floor open to the plenum became affected by the fire in the Conference Room and another execution of FIRE SIMULATOR was based on the entire floor area filling through that route. In this appraisal, extra perimeter wall area was added to account for the heat absorption capabilities of the subdividing partitions. Based on an approximation of the partitioning shown on the floor plan, the actual building perimeter was increased by a factor of three.

Appendices $A, B$, and $C$ are detailed printouts from these three runs of FIRE SIMULATOR as follows:

1. Appendix A provides the data for the estimation of conditions in the Conference Room from the start of the fire until approximately 11:28. After that time, it is believed that general smoke filling of the entire fifth floor encompassed the conditions in the Conference Room and the entire floor is best modeled as a single space.

2. Appendix B covers the average development of conditions estimated for the suite. This is also terminated at approximately 11:28 when conditions were believed to have stabilized and the further development of fire in the suite became simply another part of the general condition throughout the floor. 
3. Appendix $\mathrm{C}$ provides the printout of the estimation for the totalifiororarea. After the ceiling failure, the fire spread heat and smoke into the void and forced heated smoke through the ceiling vents into the corridors and other offices throughout the floor. To estimate the impact of this, FPETOOL was used to model the entire floor as a single area of fire impact.

Figures 8 through 12 provide graphic representation of the estimated change in environmental conditions. These graphs cover rise in temperature, estimated depth of smoke, oxygen in the smoke, carbon monoxide increases in the smoke, and vision distance through the smoke.

Figures 13 through 24 are an attempt to provide a pictorial time-line sequence showing the movement of people in contrast to the development of fire from the time of fire outbreak until the completion of evacuation of the ABMC suite. Figure 25 presents the key data and information in a single time-line.

\section{ALTERNATIVE PROTECTION METHODS}

An analysis of the likely course of events had alternative protection mechanisms been available was made. The analysis in each case is based on the presence of the mass of combustible material in the Conference Room producing a rate of heat release such as 
described in Figure 7. The impact of smoke detectors, standard or quick response sprinklers, and that of fire resistive partitions were considered.

1. Smoke Detectors - FIRE SIMULATOR indicates that a smoke detector located near the center of the Conference Room would have detected the fire at about 11:23 a.m., $11 / 2$ minutes after initiation. This would be about one minute before smoke was seen by members of the staff. The fire at that time was small and could have been attacked with a fire extinguisher. The probability of successful attack, however, is felt to be low since it would have been necessary for the staff to have recognized the alarm, discovered the point of origin, found a fire extinguisher, and correctly used it. The estimated fire growth rate at this time was such that in less than one minute following such smoke detection, the fire would be beyond attack by fire extinguisher. If not extinguished by that time, it must be expected that the fire would have proceeded in the course that it took regardless of the early detection.

2. Sprinkler Protection - The probable response of both quick response and standard sprinklers as might have been installed in the Conference Room were evaluated. FIRE SIMULATOR predicts the activation of a typical quick response sprinkler at approximately 134 seconds after initiation (or about 11:24 a.m.). This would be in a general vicinity of the time at which the staff first became aware of the fire. In addition, FIRE SIMULATOR estimates that a standard sprinkler head would have operated about one minute later at approximately 169 seconds. The normal sprinkler 
head currently used in sprinkler protected office occupancies is the standard head. This head would probably have operated at about the time Person E first observed the fire. The type of fire involved is one expected to be controlled by a normal sprinkler system in good operating order. Because of the shielding of the large conference table, it is quite possible that some burning would have continued until arrival of the fire department for final extinguishment. It is not expected, however, that any failures of ceilings, partitions, or other heat damage would have occursed: outside the room of origin. Smoke would have spread through the suite and possibly been picked up by the HVAC system and distributed through the rest of the building. While such smoke could be quite dark, it would be cool, high in oxygen, and low in noxious or corrosive materials. The smoke and fire gases would not have been hot enough to rupture the PCB containing condenser in the light ballasts. The printout of the FIRE SIMULATOR runs used to form these conclusions is contained in Appendix D.

3. Fire Resistive Partitions - Many newer office buildings subdivide each suite from the corridor and from any other suite by fire resistive partitions extending from floor to slab. Had such been present, the fire would have been confined to the ABMC space and the ceiling spaces above it. Damage in that space would have been at least as extensive as that which actually occurred. Since the fire would have vented into a much smaller plenum, it is quite possible that fire damage would have extended ovel wider range of the $\mathrm{ABMC}$ space. At least as many ballasts would probably have 
been involved and the extent of spread of contaminated smoke would have then depended upon the presence or absence and operation or failure of fire and smoke dampers in the distribution system.

\section{CONCLUSIONS}

The fire events and conditions predicted using thercalculation procedures in FPETOOL give a rational explanation of how the fire developed and what factors determined its course.

The most likely source of ignition is an electrical short in the lamp cord for the podium lamp, causing this to flame and ignite the adjacent corrugated boxes. The fire developed rapidly due to the characteristic rapid burning rate of the initial fuel (corrugated boxes). The occupants had no chance to alter the sequence of events given the conditions at the time of discovery. Collections of combustible materials in the quantities that existed in the Conference Room always present major hazardous potentials. Established fire safety criteria as found in building codes and Federal agency criteria ${ }^{6}$ would require that such combustible concentrations be enclosed in fire resistive rooms or protected by automatic sprinklers.

${ }^{6}$ Most Federal agencies use the Life Safety Codc published by the National Fire Protection Association as part of their criteria. Section 27-3.2.1 of the 19SS edition of that code addresses hazardous areas in existing office buildings. That paragraph requires either sprinkler protection or a fire resistive separation for hazardous areas including those used for general storage. 

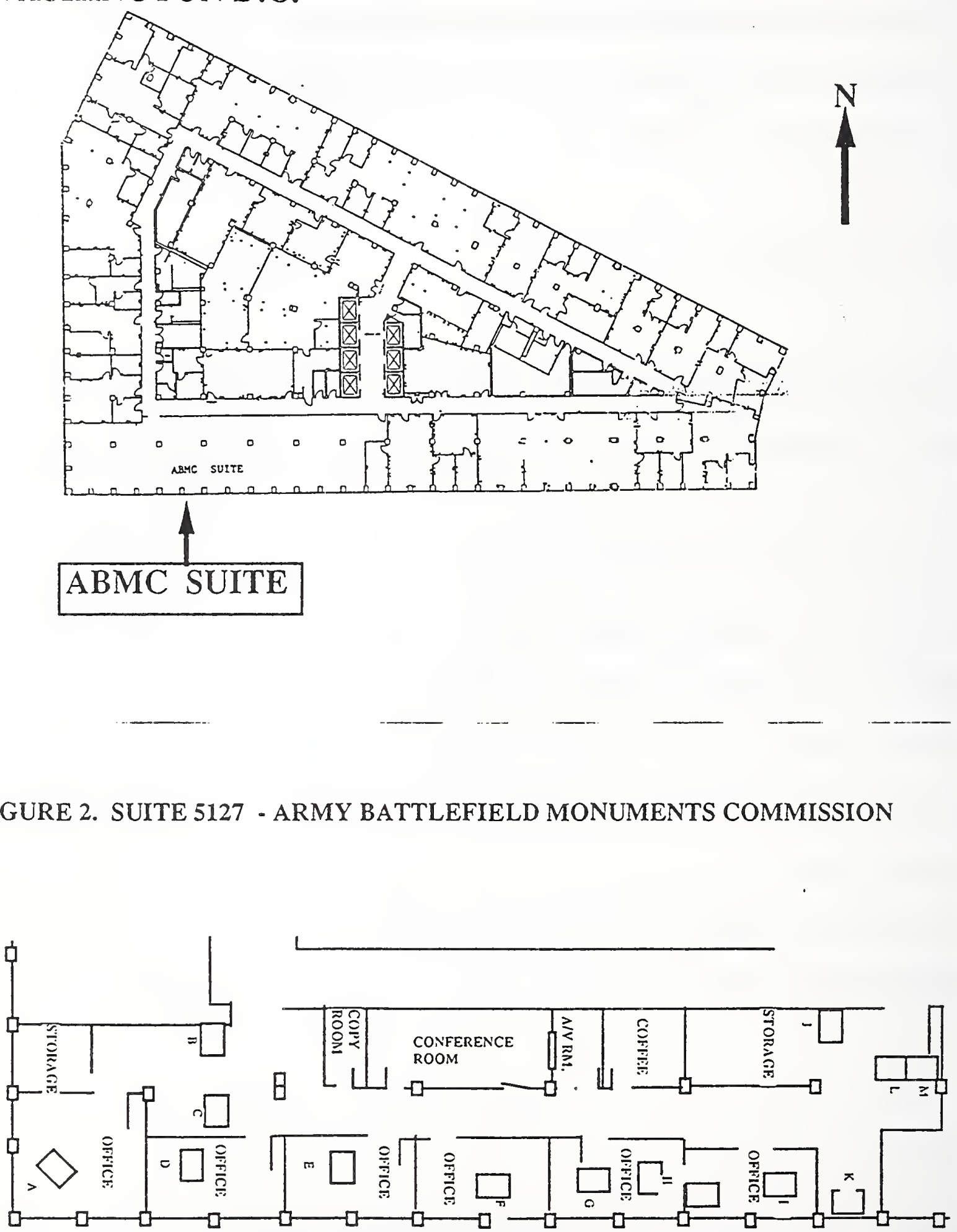
FIGURE 3 FAN ROOM ELEVATION (TYPICAL)

PLENLIN RETURN

MAKE UP AIR

THROUGH COMMON SIIAFT

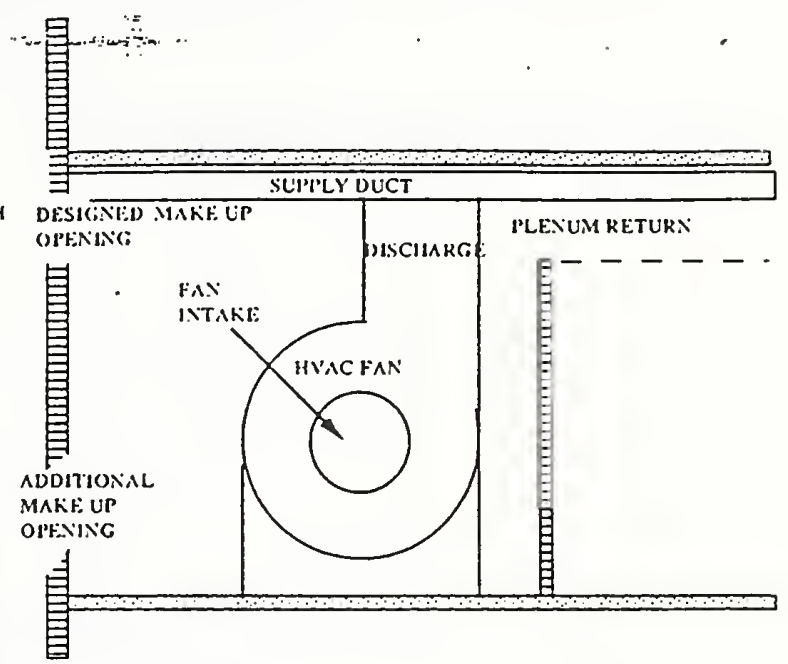

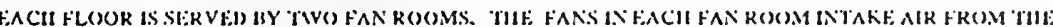

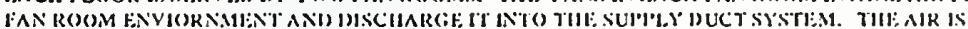

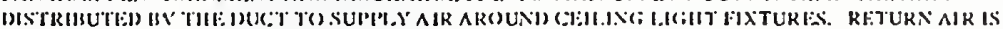

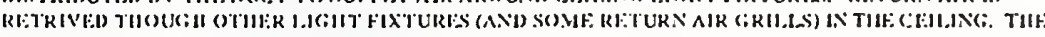

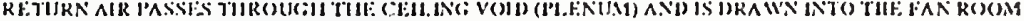

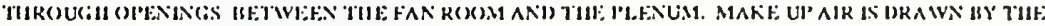

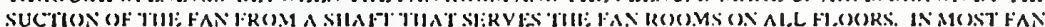

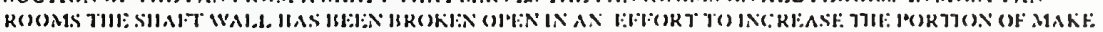

UI AIR. 
CONFERENCE ROOM

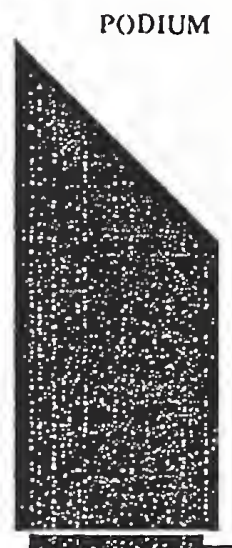

PORTION OF CORD WRAPPED WITII FRICTION TAPE

\section{FIGURE 6. EST. FLAME EXTENSION ABMC FIRE OF 3-23-1990}

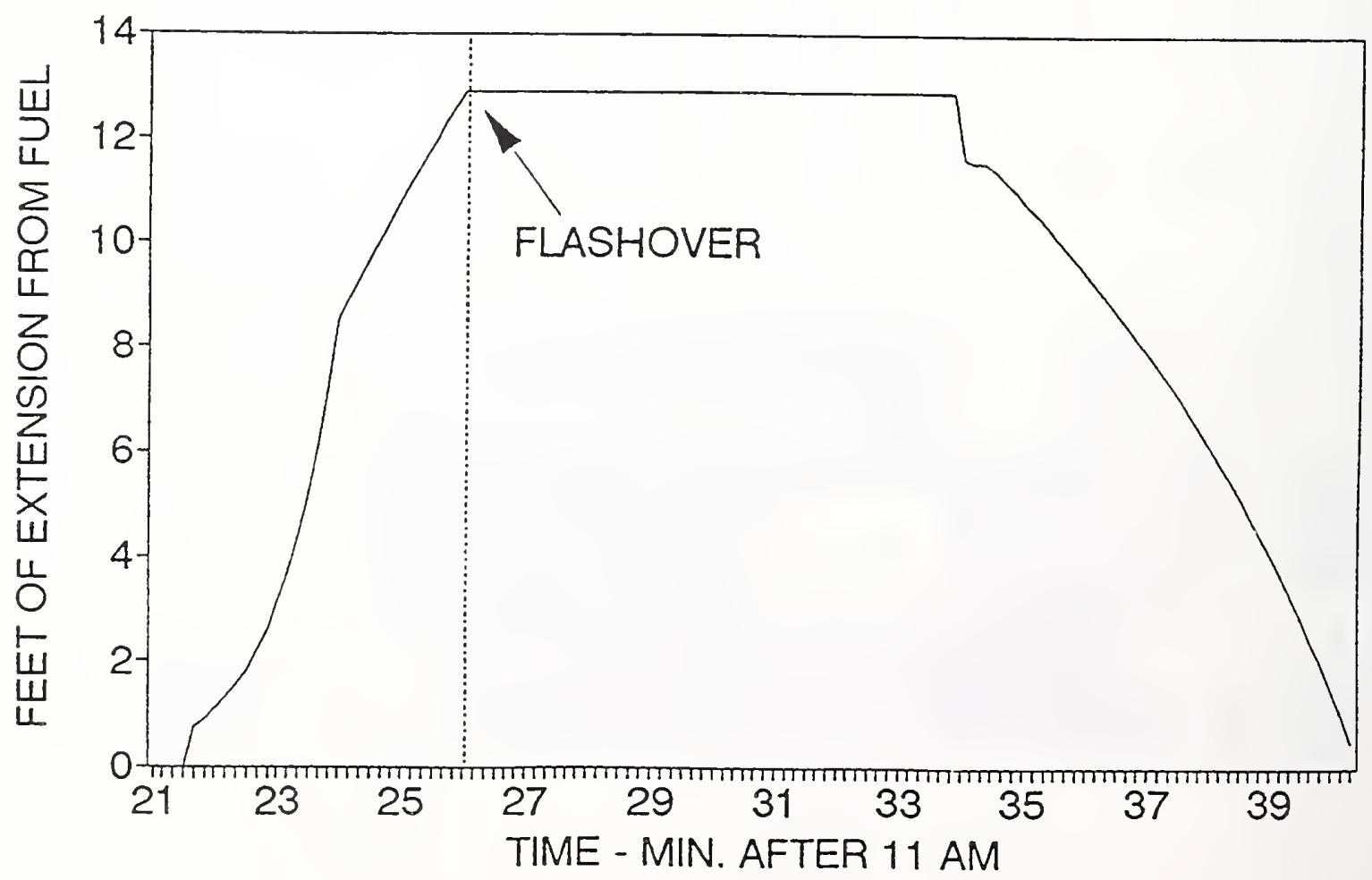




\section{FIGURE 7. ESTIMATED FIRE SIZE ABMC FFIED $3-23-1990$}

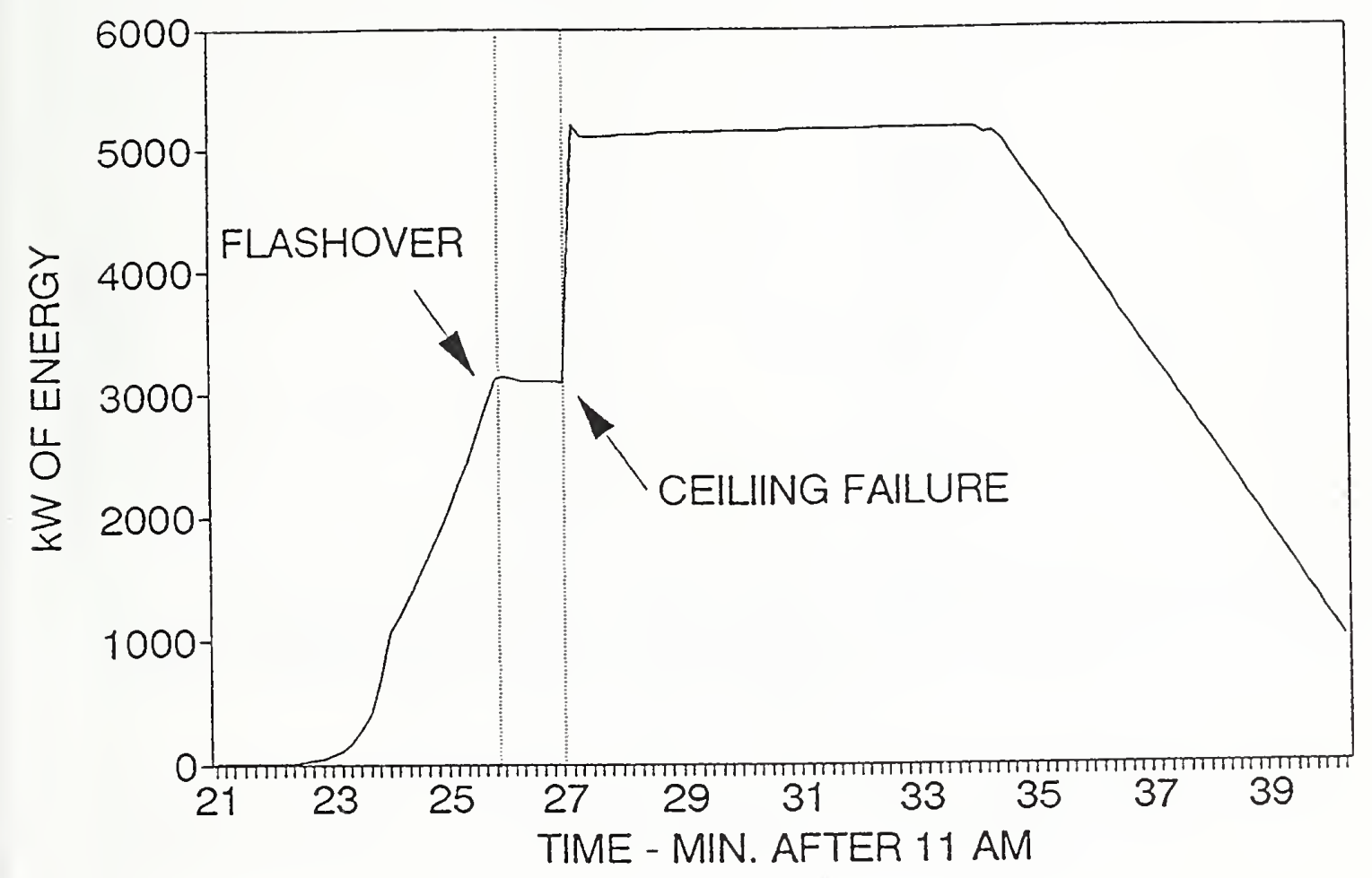

FIGURE 8. SMOKE TEMPERATURE ABMC FIRE OF 3-23-1990

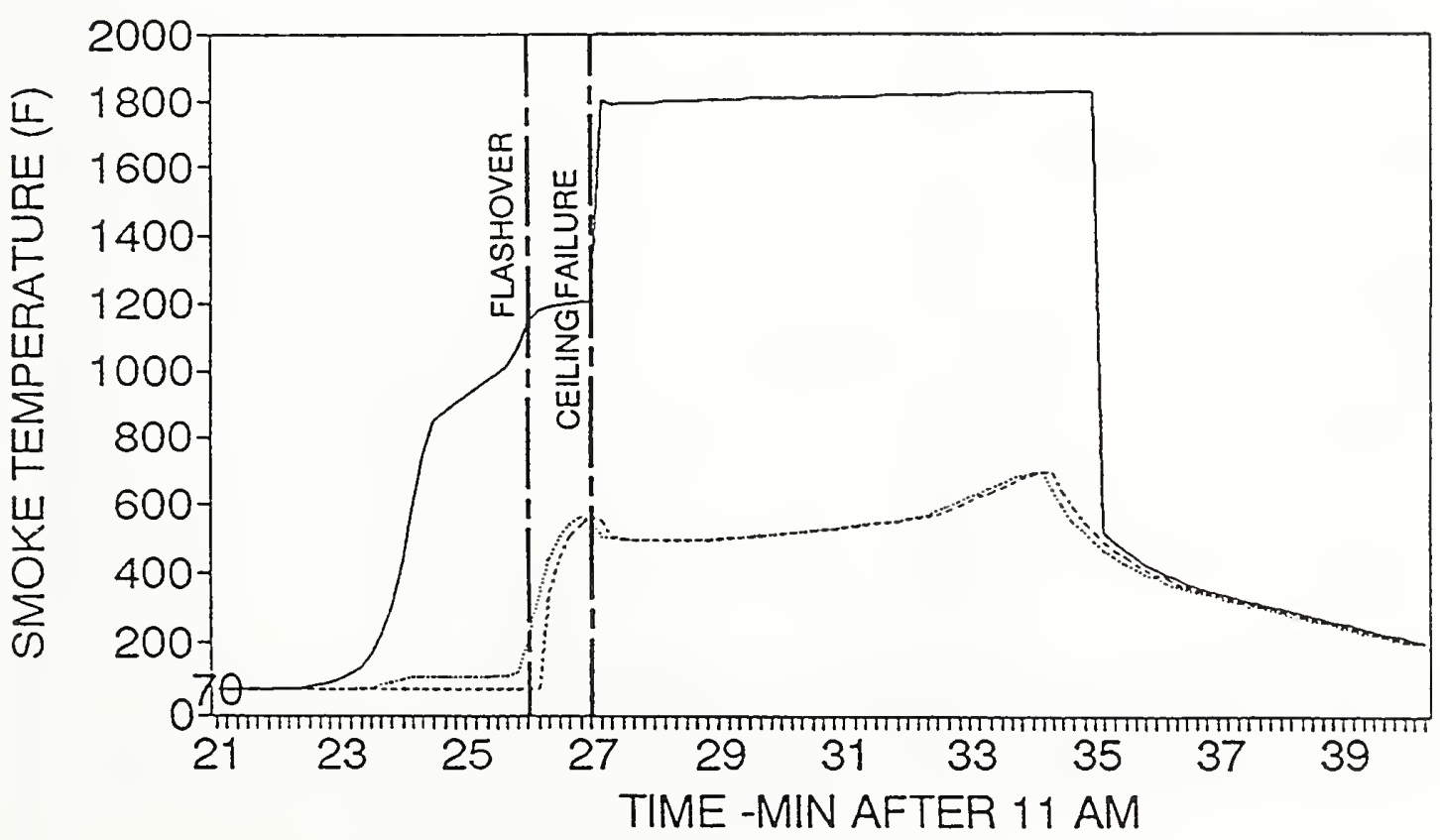




\section{FIGURE 9. SMOKE LEVEL \\ ABMC FIFE QF 3-23-1990}

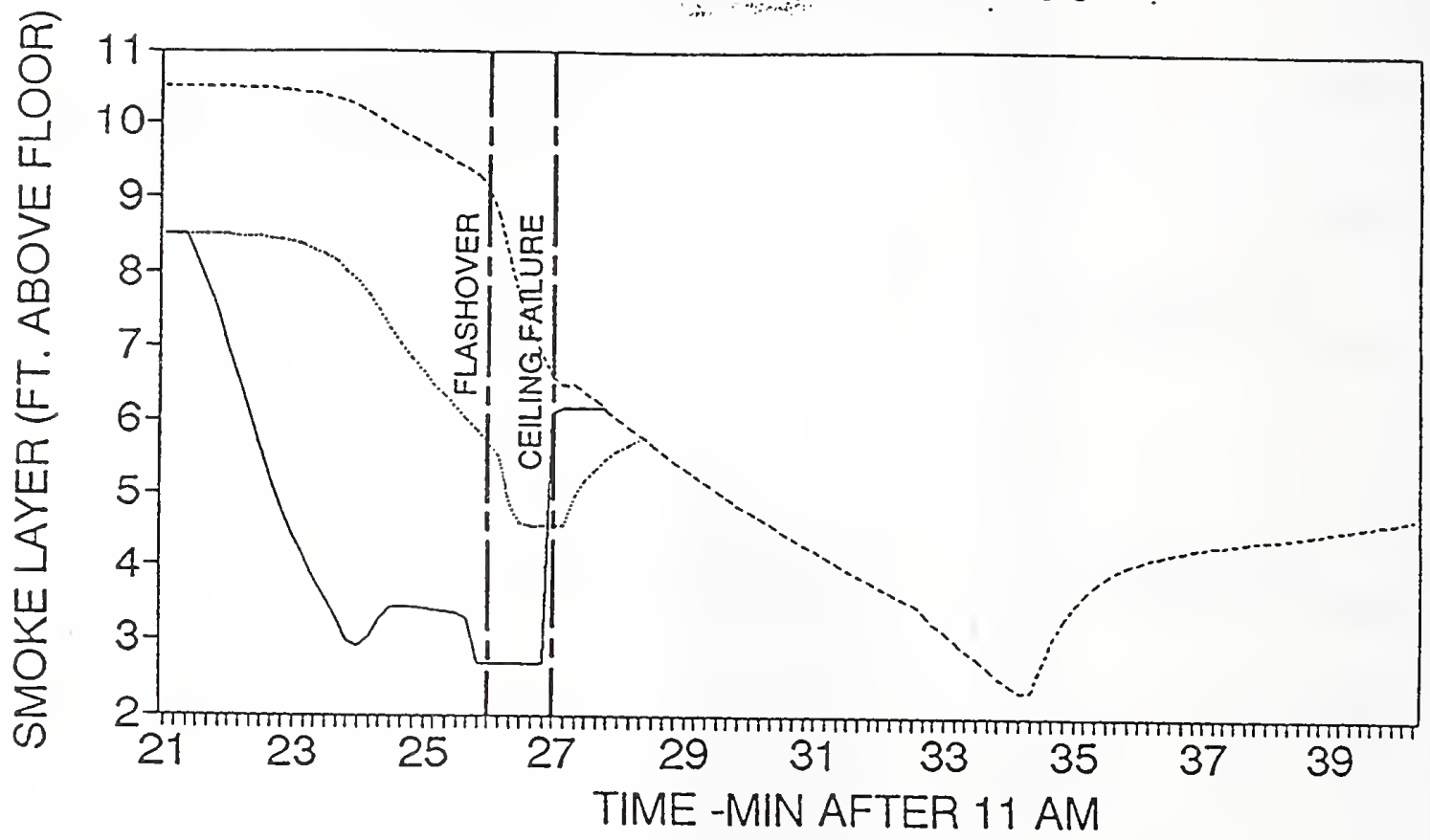

\section{FIGURE 10. OXYGEN IN SMOKE ABMC FIRE OF 3-23-1990}

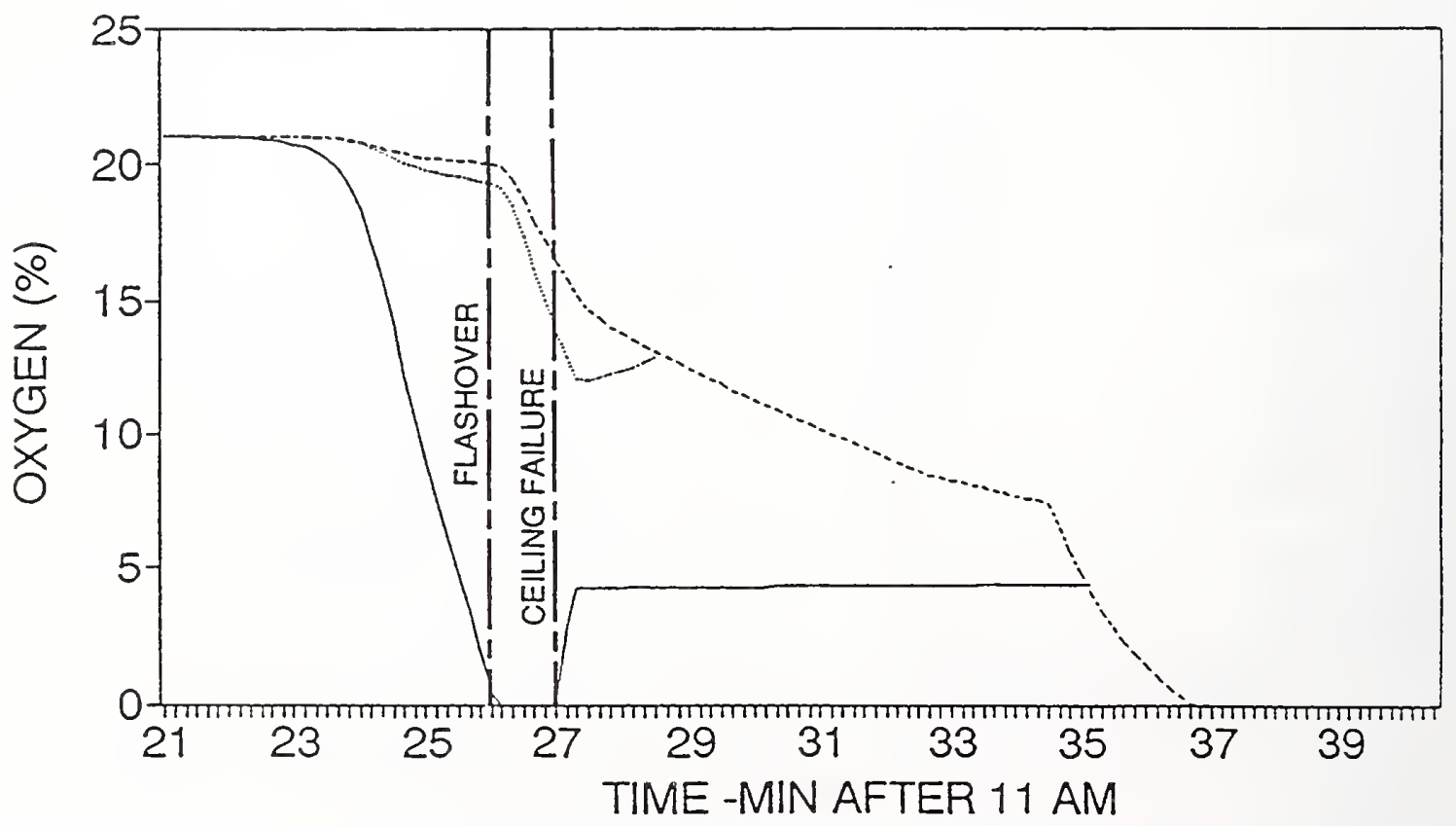




\section{FIGURE 11. CO IN SMOKE ABMC FIRE OF 3-23-1990}

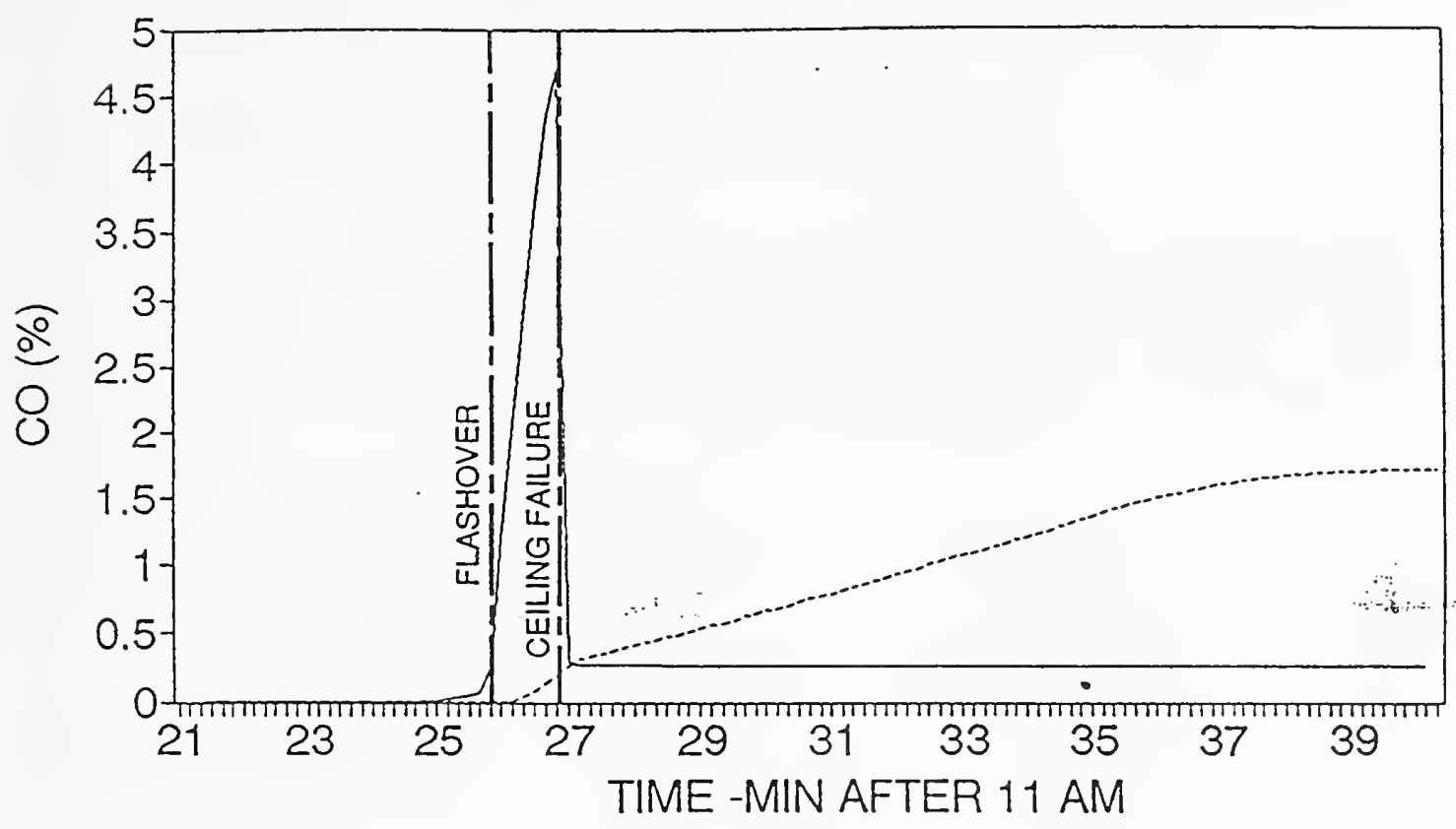

CONF. RM. ……... OTHER AREAS

\section{FIGURE 12. EST. VISION IN SMK. ABMC FIRE OF 3-23-1990}

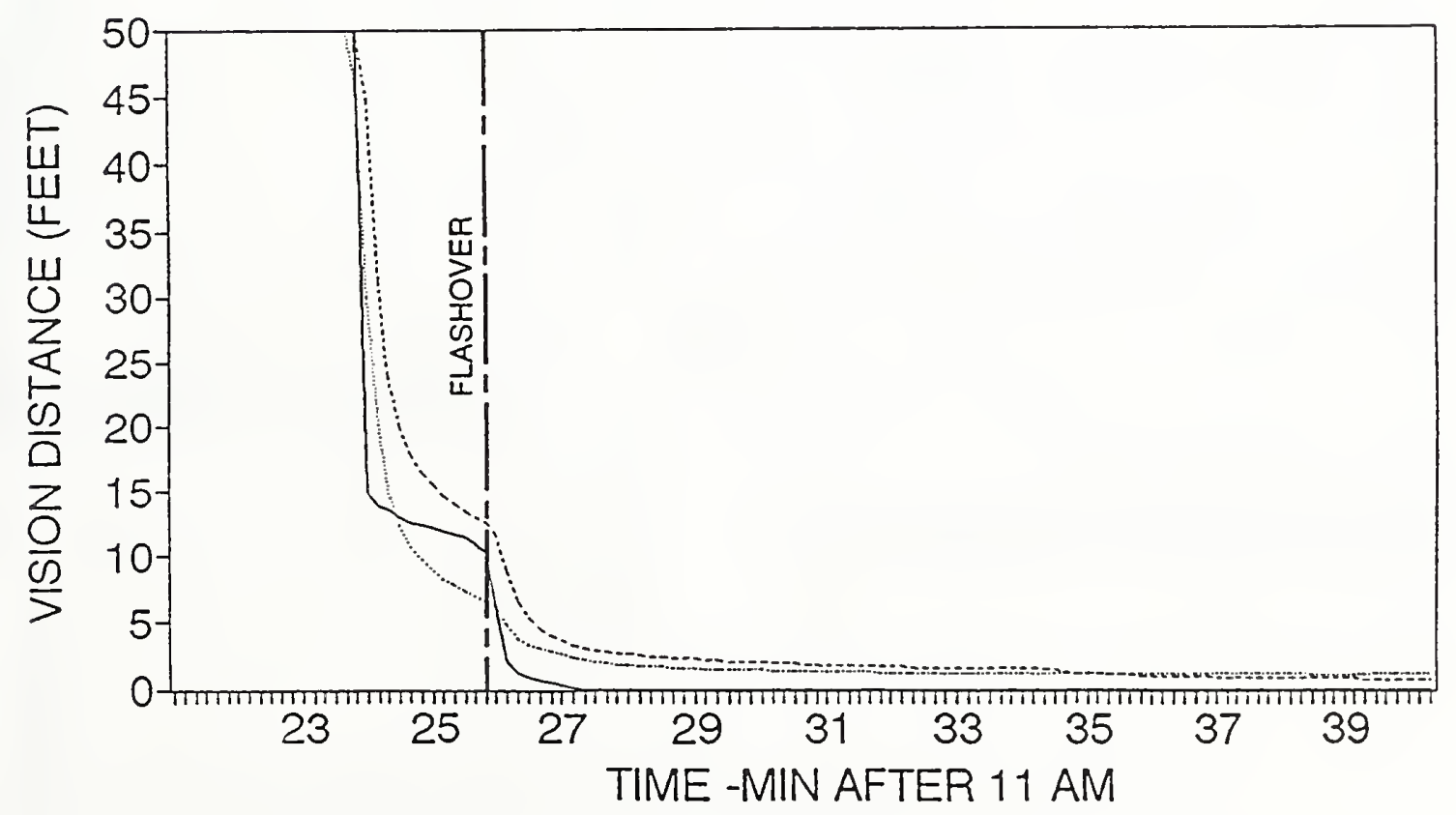




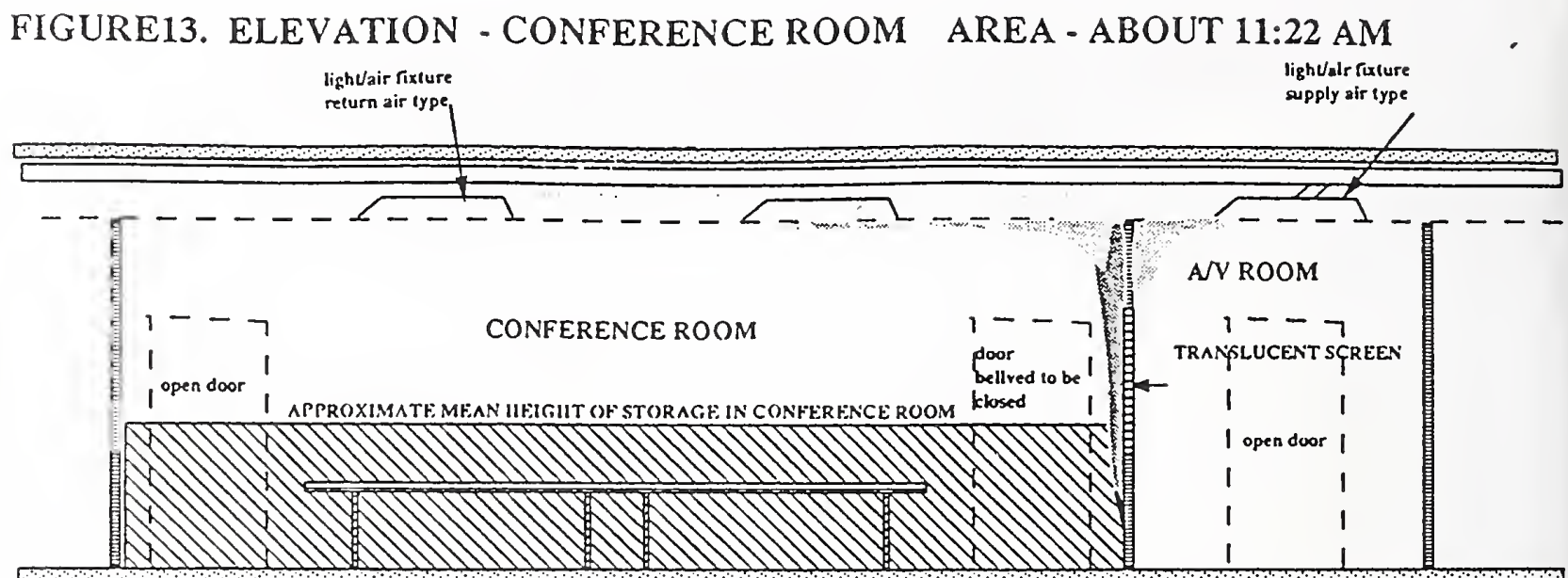

OPEN FLAMING HAS STARTED PROBABLY DURING THE PRECEDING MINUTE.

FIRE IS ABOUT IOKW. FLAME IS LESS THAN I-FOOT HIGH IIAND FIRE EXTINGUISIIER WOULD BE EFFECTIVE.

-

TIIIN SMOKE IS ACCUMULATING; AT TIAE CEILING; SOME IS UBEING; PULLED INTO TIIE CEILING RLETURN, IT IS LIKLI,Y TIIAT SOML SMOKE IS SEEPING INTO THE A/V ROOM. A I'OSSIBLE ROUTE BEING AROUND TIIE TRANSLUCENI SCREEN.

SMOKE IS STILL COOL AND ONLY A LIGIIT IIAZE. IESTIMATED TEMPERATURE RISE AT TIIIS TIME IS I.F.SS TIIAN 5 I)I:(BREES l:

A SMOKE DETECTOR WOULD IIAVE OPERATED SOON AFTER TIIS TIME (HAD ONE IBEEN PRESEN'T)

REINFORCED CONCRETE BUILDING. GYPSUM BOARD ON METAL STUD, CEILING HIGH PARTITIONS.

RETURN AIR PLENUM ()VER N(ON-FIRE RATED CEILING.

AIR TIRANSIFER TIIROUGII LIGIIT FIXTURES - SOME SUPI'LY,SOME RETURN (LOCATIONS SIIC)WN MAY NOT IBE ACTUAL LOCATIONSAT TIME OF FIRE.

FIGURE 14. ACTIVITIES IN ABMC SUITE - ABOUT 11:15 TO 11: 22 AM

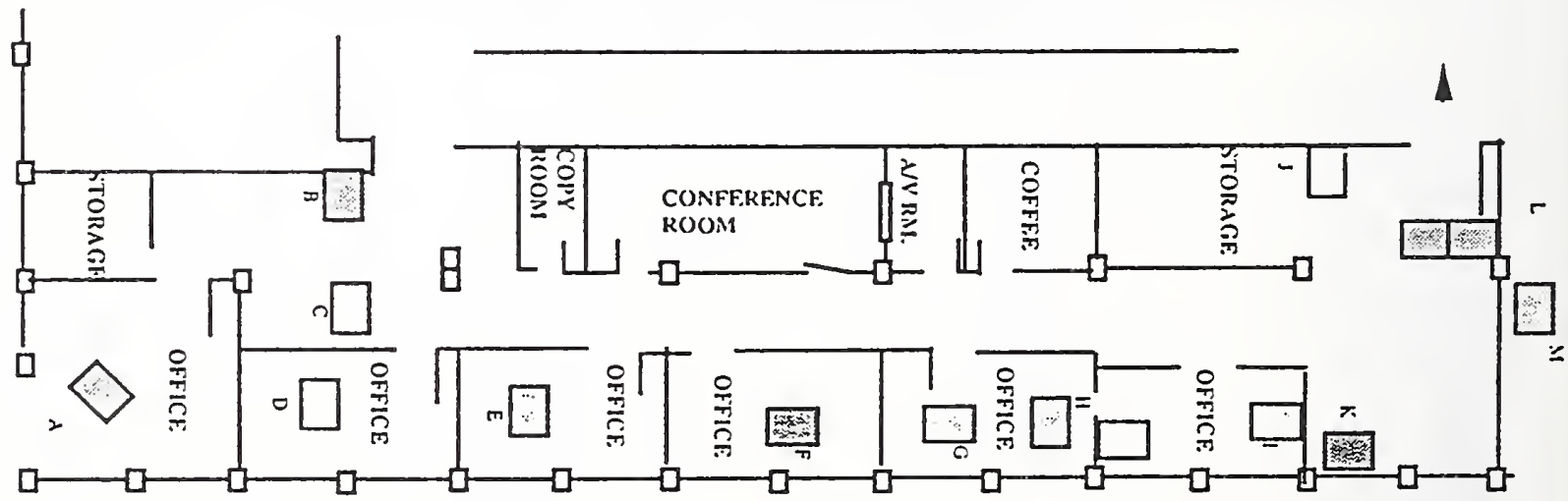

- PERSONS F \& K LEAVE ABMC.

- PERSON K IIAD BEEN IN AVV ROOM AT ABOUT 10:16 AND PERSON F PASSED EAST (CLOSED) DUOR OF CONFERENCE ROOM $A S$ HE LEFT. NEITHER NOTED ANYTIHING UNUSUAL 


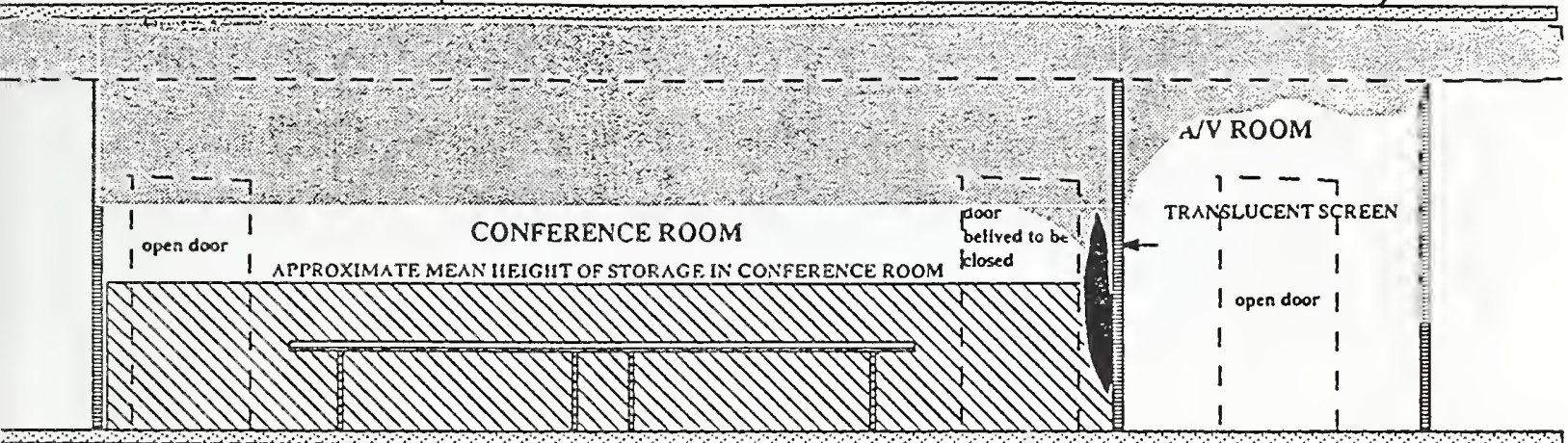

FIRE IS ABOUT $100 \mathrm{KW}$ (LARGE WASTE BASKET) SIZE. IS CLOSE TO TIE MAXIMUM SIZE WIERE IIAND FIRE EXIINGUISIIER WOULD BE EIIECTIVE.

A NOTICEABLE TIHIN SMOKE IS ACCUMULATING AT TIIE CEHING. MORF IS IBEING PULLED INTO TIE CEILIN(; RETURN.AND SLEPIN(; INTO TUE A/V ROOM.

SMOKE IS WARMER BUT STILL ONLY ABOUT 100 DE( GREE R. IIOT (BAS JET ACROSS

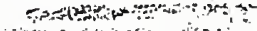
CEILING IS CLOSETO 200 DECIREESI:.

SMOKE LEVEL IS DOWNTO OR MAST TIIETOP (OFTHEOPENDOOR. A SMALA, AMOUNT IS PROBABLY FLOWING INTO THE ABMC CORRIDOR.

FLAME IS ABOUT 5 FEET HIIGH.

THIS APPROXIMATLY THE TIME WIIEN A QUICK RESPONSE SIRINKLER IVOULD IIAVE OPERATED (IF PRESENT)

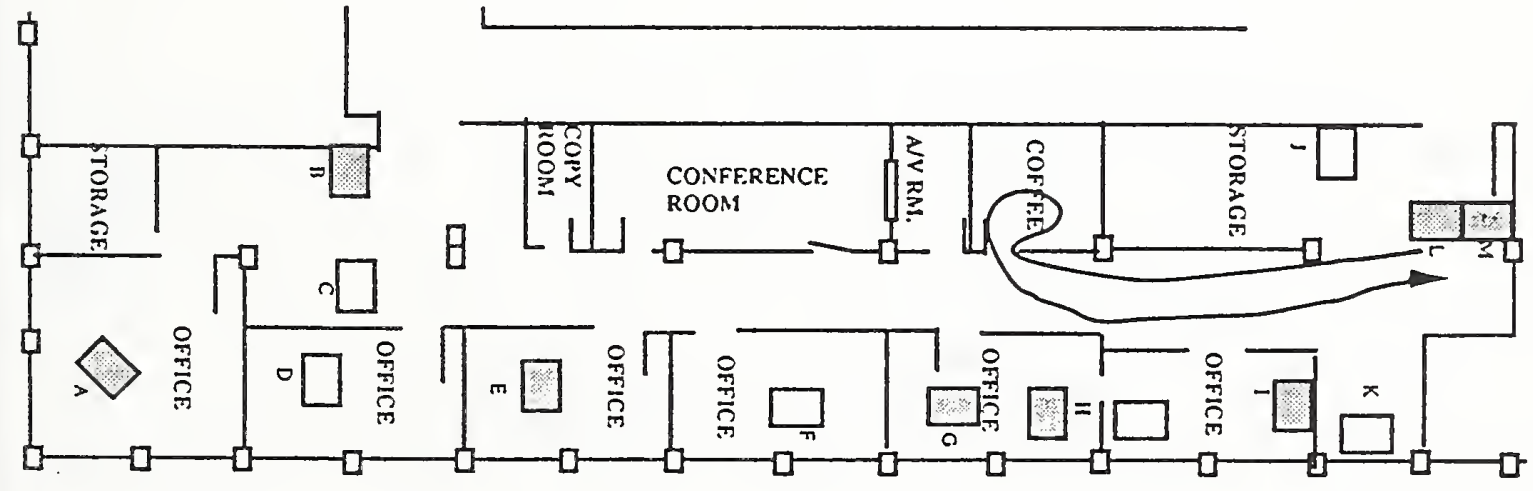

PERSON L TRAVELS TO COFFEE ROOM, OBTAINS CUP OF COFFEE AND RETURNS TO HER WORKSTATION. REPORTS NOTHING.

OCCUPANT AIVAY FROM ABMC AT THIS TTME OCCUPNATIN ABMC SPACE AT TIIS TIME 


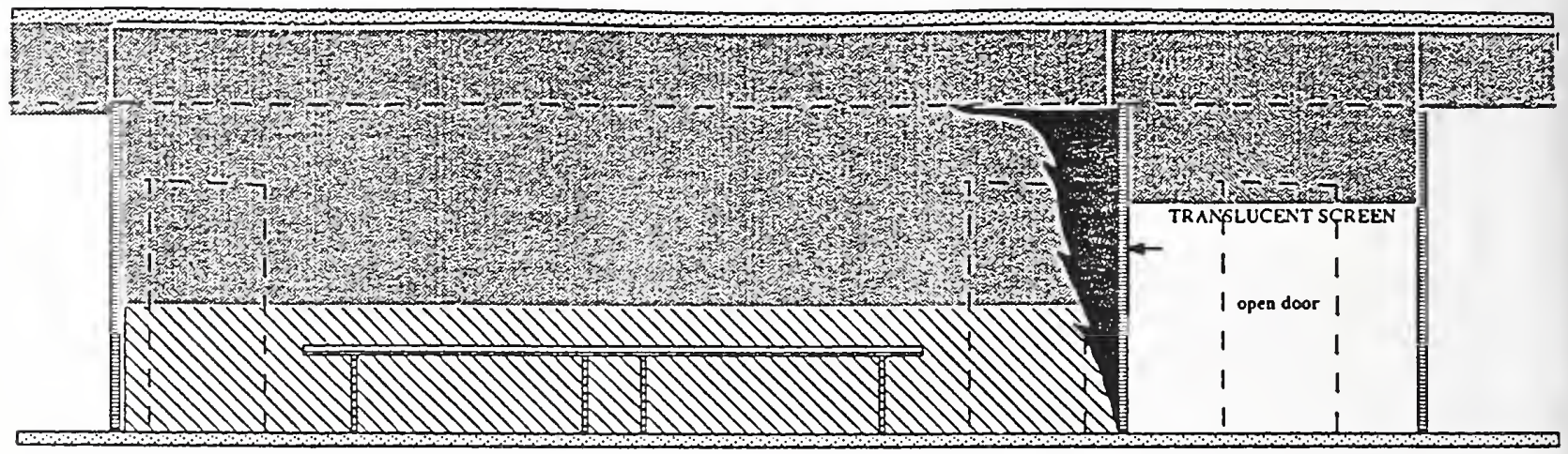

FIRE IS ABOUT $800 \mathrm{KW}$ (AS BIG AS A FULLY INVOLVED UPHOLSTERED EASY CHAIR.) SIZE IS TOO LARGE FOR HAND FIRE EXTINGUISHER ATTACK.

A GRAY SMOKE IS IN THE UPPER HALF OF THE ROOM. THE SMOKE IS CLEARLY EVIDENT BUT DOES NOT YET BLOCK OUT A SIGNIFICANT QUANTITY OF LIGIIT FROM TIIE CEILING; FIXTURLSSOER

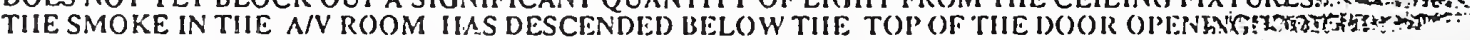
SMOKE IS BEGINNN(; TO BE RECIRCULATEI) BY THE BUILDING FANS.

SMOKE TEMPERATURE IS APPROACHIN(; 400 F.

FLAME EXTENTION IS NOW IN TIIE RANGE ()F 9 -II FEET AND STARTING' TO BEND ACROSS TIE CEILING.

A STANDARD SPRINKLER IIEAD WOULD HAVE OPERATED ABOUT 30 SECONDS PRIOR TO TIIS TIME (IF PRESENT)

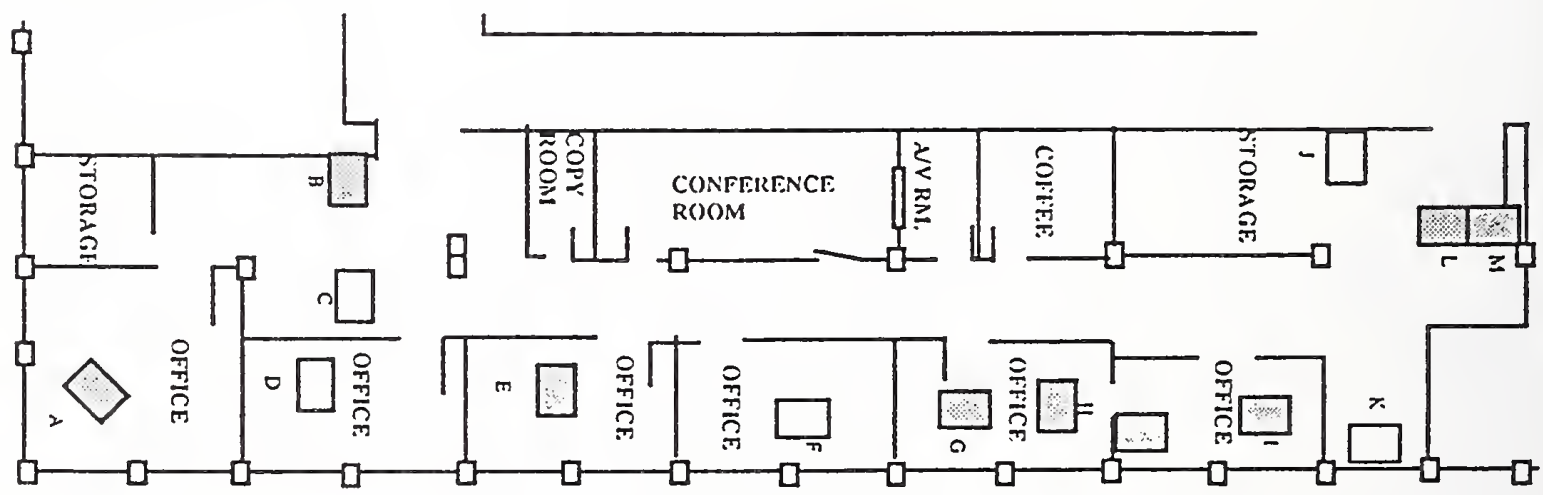

N() ACTIVITY RELEATED TO TIIE FIRE IS KNOWN TO IIAVE ()CCURED IN TIIS TIME PERIOD.

OCCUPANT AWAY FROM ABMC AT THIS TIME:

OCCUPANT M ABMC SPACE AT TIIS TIM: 


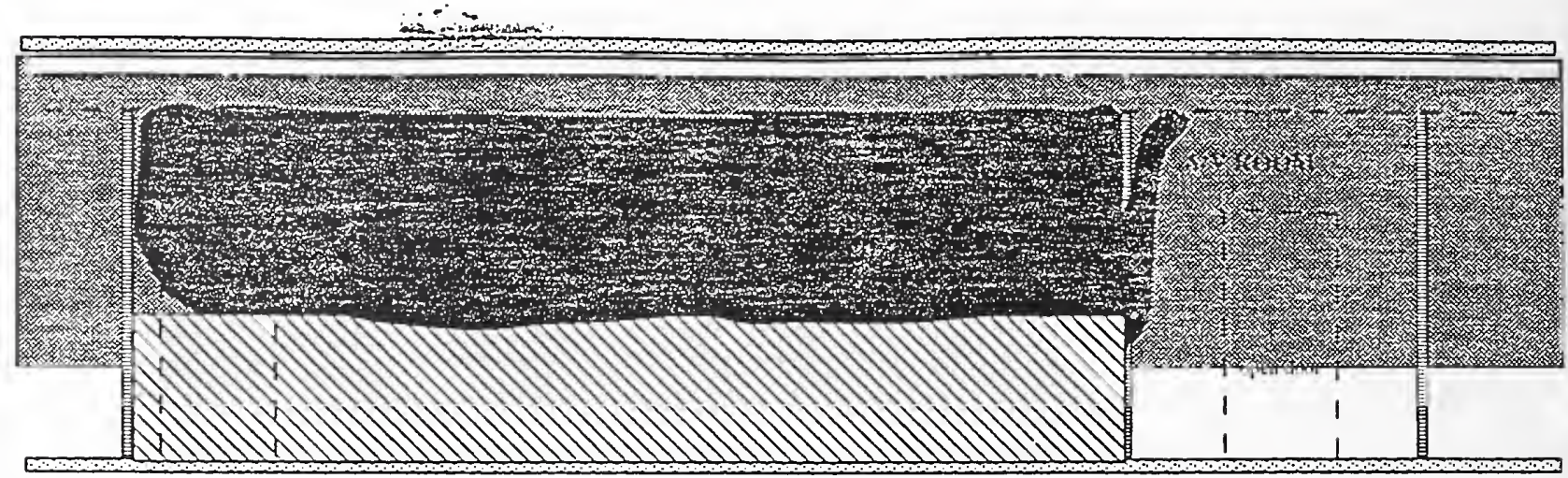

FLASIIOVEIR OCCUIRS - TIIE EXPOSED SUIRFACES OF ALL COMIBUSTIBLE MATERIALS ATTEMIT TO IGNITE. TIIE ACTUAL BURNING IN TIIE ROOM IS LIMITED ISY THE RATE TIIAT AIR CAN BE DIRAWN INTO TIIE ROOM. UNBURNED FUEL GAS VENT AS FLAME INTO TIIE ABMC CORIRIDOR.

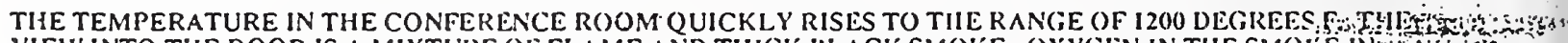

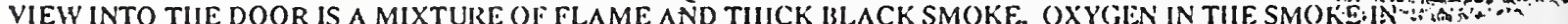
TIIE CONFEIRENCE ROOM DIROI'S TO NEAR ZERO. TIIE CARIBON MONOXIIDE CONCENTIRATION IN TIIE SMOKE RISES TO 3 TO $4 \%$.

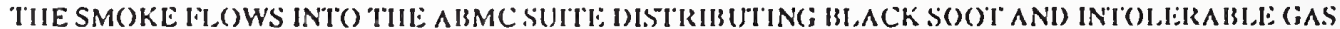

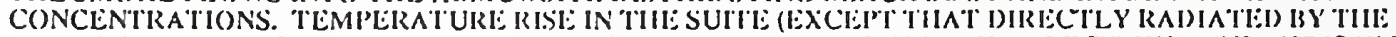
FLAME FROM TIIE CONFERENCE IROOM) RISES ENOU(GIITO BE INIOLERABLE TO IIUMANS IUUT IS WELL BELOW TIIAT REQUIRED TO IGNITE TIIE FURNITURE AND OTIIER MATERIALS IN TIIE SUITE.

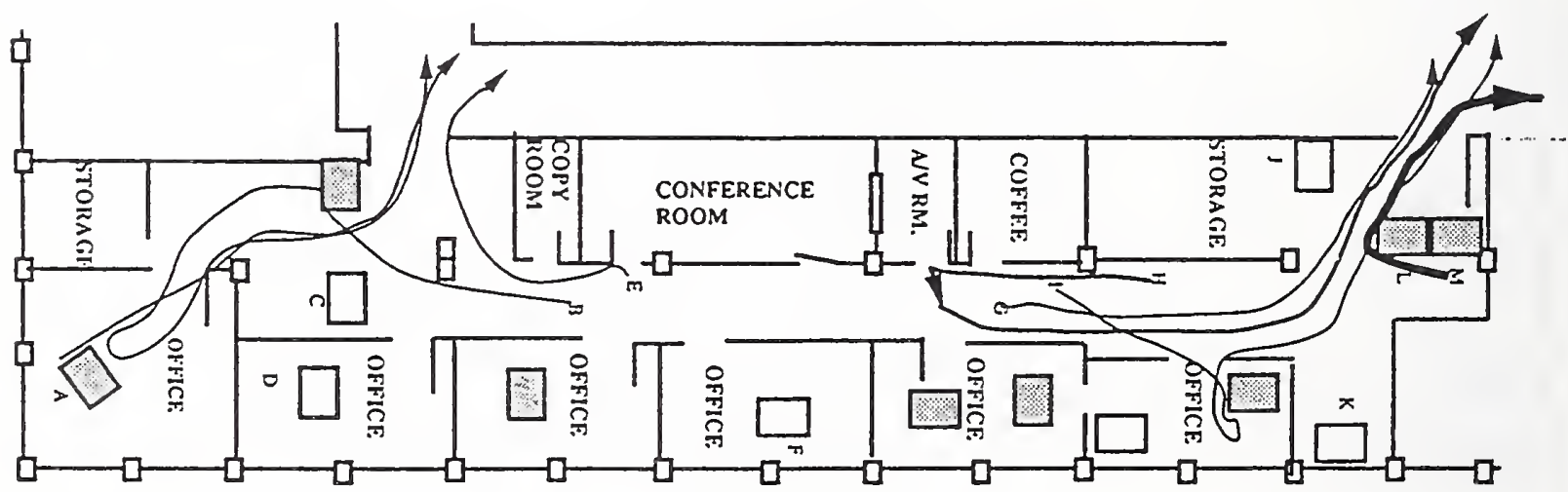

-PERSON (; EXITS SUITE TIIROUGII EAST DOOR.

- I'ERSON II RETURNS TO NV ROOM IFOR SECOND LOOK SEES SMOKE COOMING OUT OF A/V ROOM DOOR. LEVEL OF SMOKE IN ANV ROOM DOORWAY AT ABOUT CIIEST LEVEL. TIII:N EXITSS SIACE TIIROU(BII EAST DOOR.

- P'ERSON I (GOES TO DESK, GETS I'URSE, EXITS SUITE 'TIIROUGII EAST DOOR.

- PEERSON LSEEN LOOKING DOWN SUITE IIALLIVAY, TIIIEN TURNS, JOINS PIIRSON M, LEA VES SUITE TIIROUGII EAST DOOR AND ATTEMII'T' 'TO OPERATE FIRE ALALM IBOX' SIGIITLY EAST OF EAST DOOR.

- PERSON M JOINS PERSON L IN LEA VING SUITE

- PEIRSON B RETURNS TO DESK CALLS IBUILDING MANA (iER'S OFFICE TO REIOIRT FIRE. INFORMS PERSON A ()F FIRE AND ESCORTS IIIM TO BUILDING CORRIDOR, TURNS OVEI (IUIDANCE (OF PERSONA T'O P'ERSON E.

- PERSON E LOOKS AGAIN INTO CONFERENCE ROOM, SEES SMOKE "BOILIN(;", CONCLUDES THAT IT IS NECESSARY TO LEA VE, EXITS TIIROUGII WEST DOOR,'SEES PERSON B CALLING IN FIRE ALARM AS IIE PASSES IIER DESK, IIEARS BUILDING FIRE ALAIRM AT TIIAT TIMIE. 


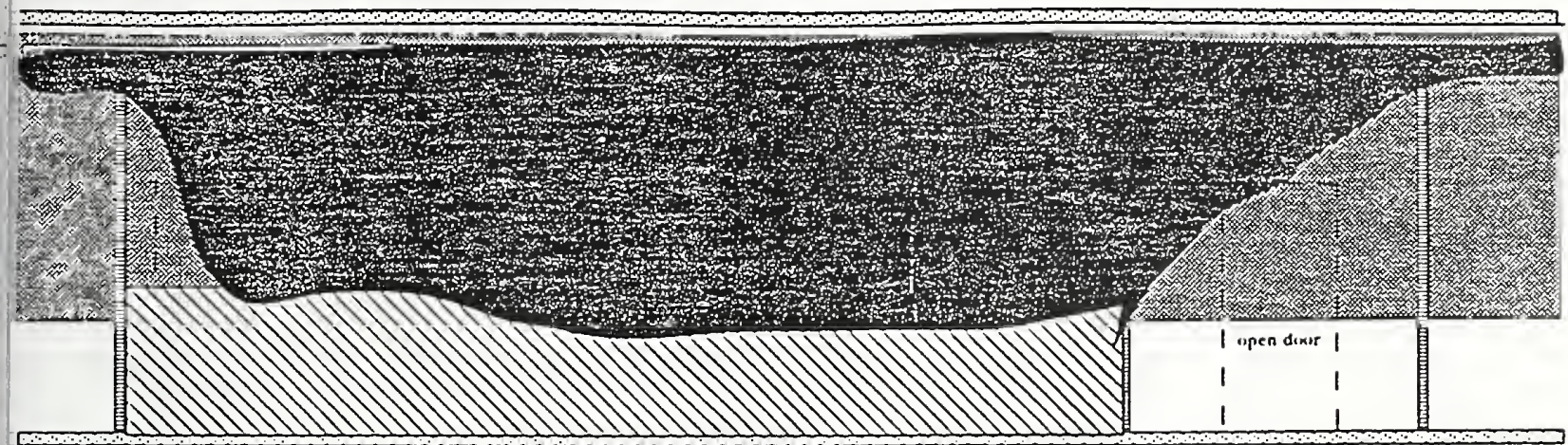

CEILING FAILS (PROBABLY IN SECTIONS). FLAME IS VENTED INI') CEILING PLENUM SPACE. SMOKE ROUTE CIIANCES. LITTLE, IF ANY, MORE SMOKE FLOWS TIHROUGII CONFERENCE ROOM DOO)R INTO AHMC SIACE. DESTIRUCTION CONTINUES IN THE CONFERENCE ROOM AND ADJACENT SIACHS ANDTTH' : $\because \cdots$ ENTIRE FLOOR RAI'IDLY FILLS WITII SMOKE GENERATED BY TIIEFIRE, FLOIVED INTO THE PLENUM SPACE ANI) DESCENDING INTO TIIE GENERAL FLOOR SPACE THROUGH TIIE CEILING LIGIITING FIX'TURES AND) ()TIIER CEILING OI'ENIN(SS. BY ABOUT II:35 AM ENTIRE IRLOOR IS FILLEI) WITII SM()KI: TO A LEVEL I TO 2 FEET ABOVE TIIE FLOOR.

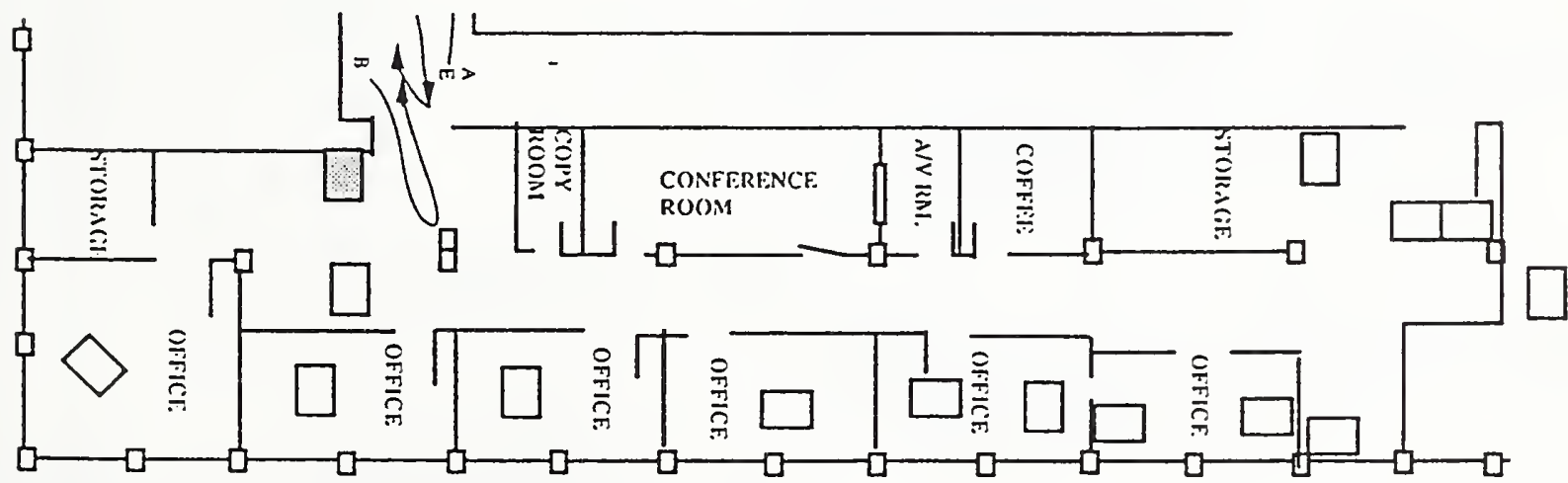

- PERSON E ESCORTS PERSON A INTO STAIRWELL, THEN RETURNSTO IVEST ENTRANCE (OF ABMC SUITE ,CALLS IN TO ASSURE TIIAT ALI, (OCCUPANIS ARI: (OUI. IINIJS IB IIAS RE-ENTIELED SUITE.

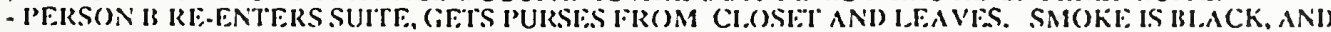

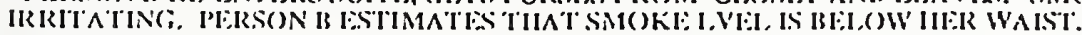
- PIERSONS IS A IETHEN LI:AVERTOOR.

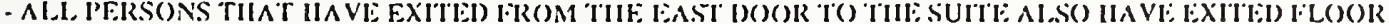

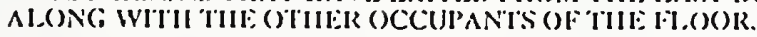




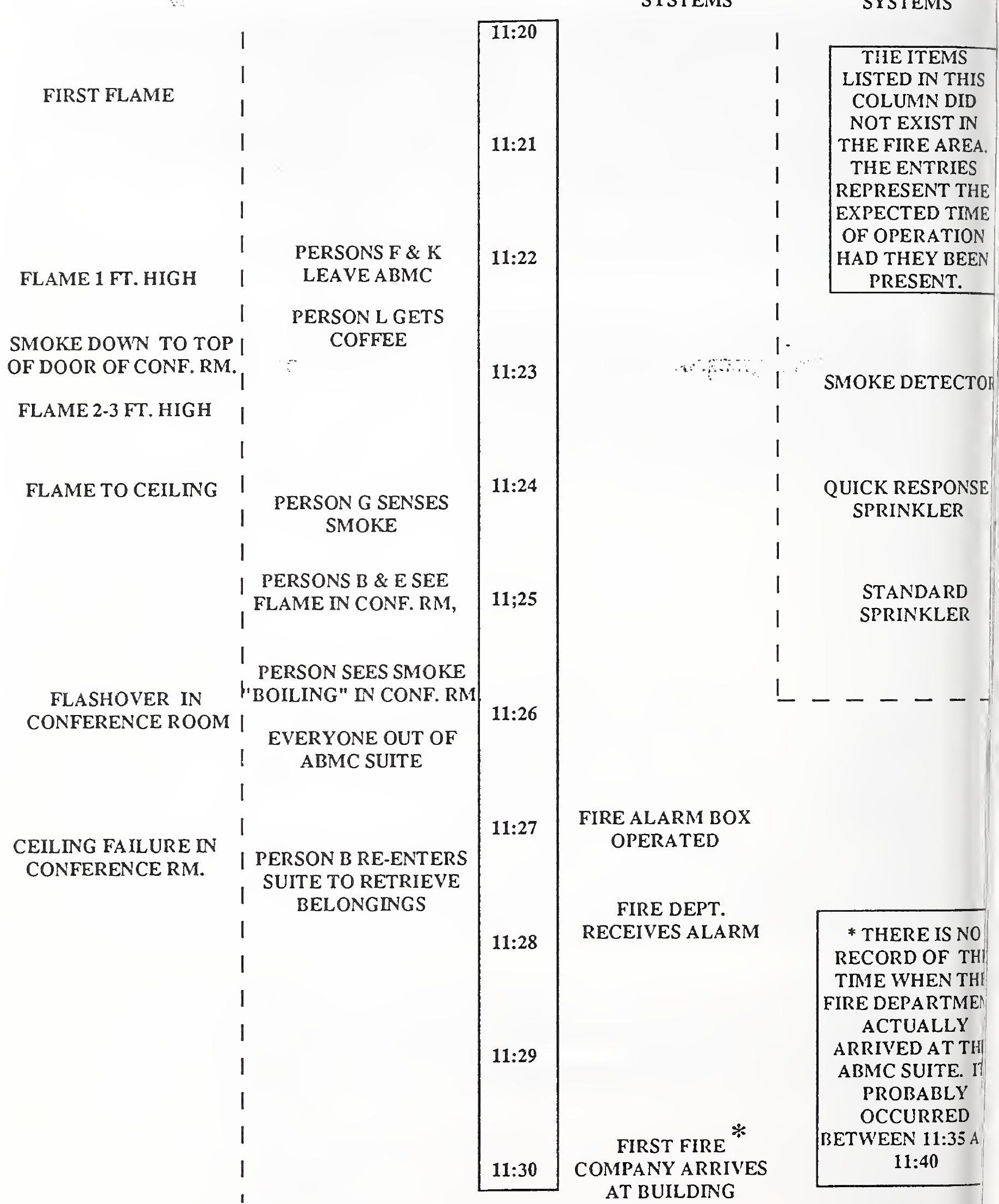




\section{APPENDIX A}

Printout of results of FIRE SIMULATOR run for the Conference Room

The printout cnntained in this appendix is actually the combination of two runs of FIRE SIMULATOR. The two runs ivere identical except that the run used for the first 210 seconds estimated the specific"extinction coefficient as $30 \%$ of that estimated for the remainder of the run.

Also at 330 seconds into the run, the size of the room opening was revised to simulate
massive failure of the ceiling system.
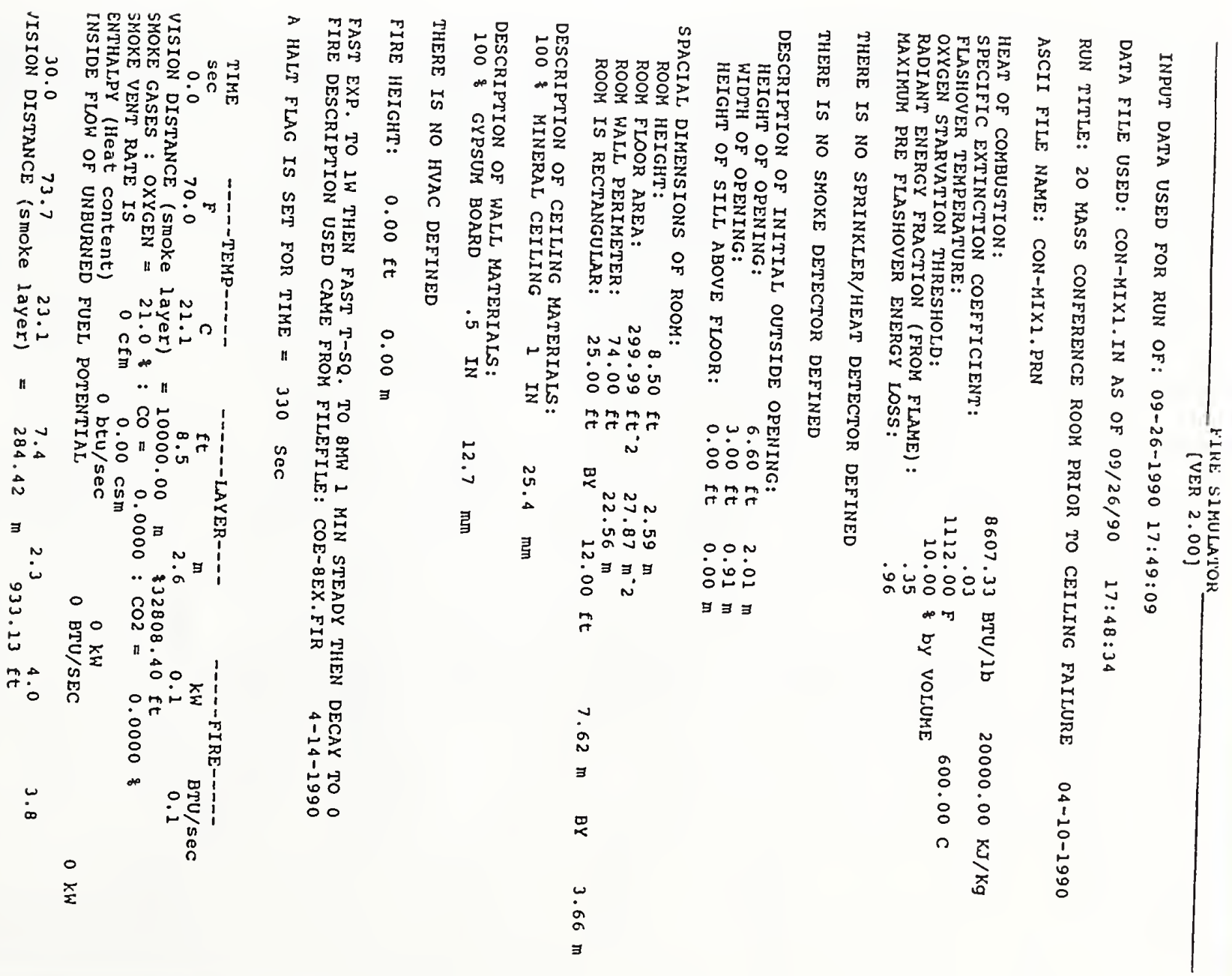


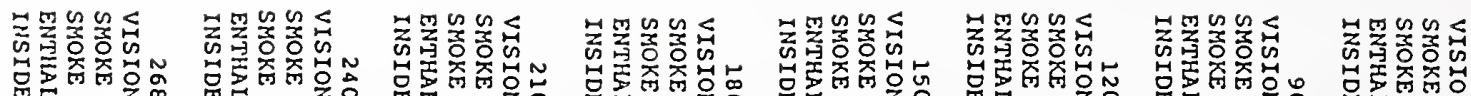

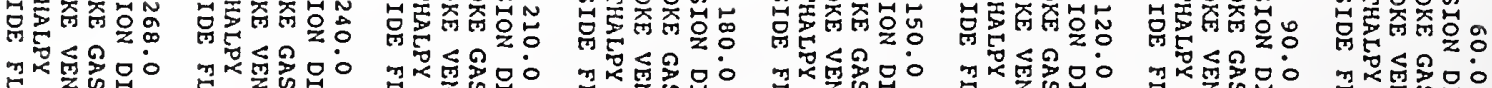

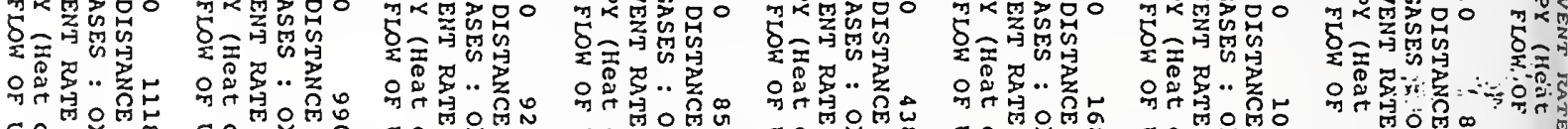

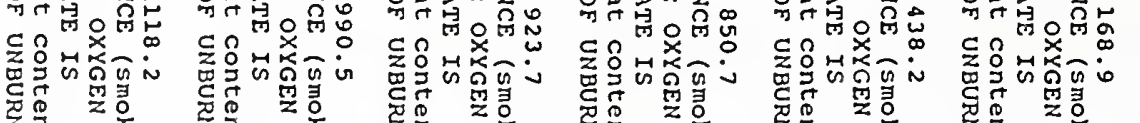

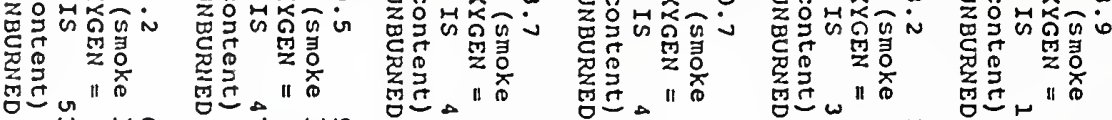

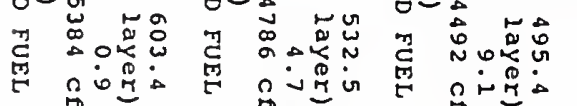

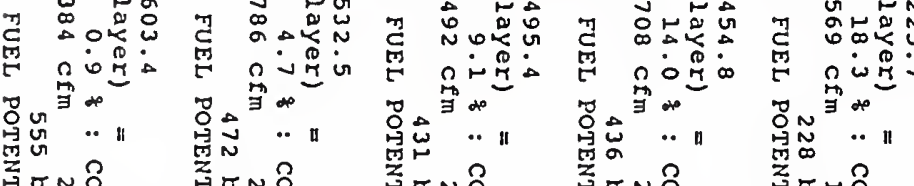

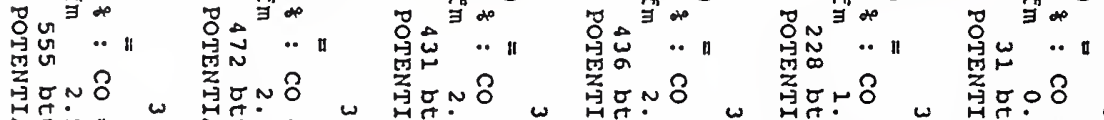

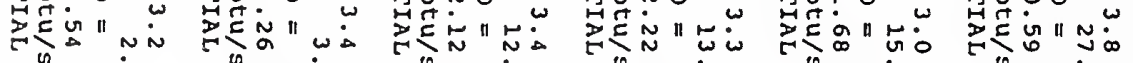

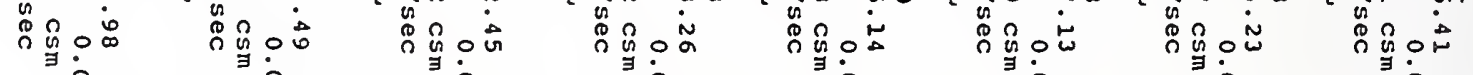

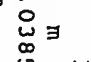
. !
:

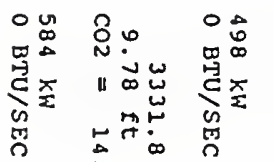

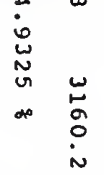

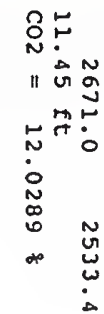
줄

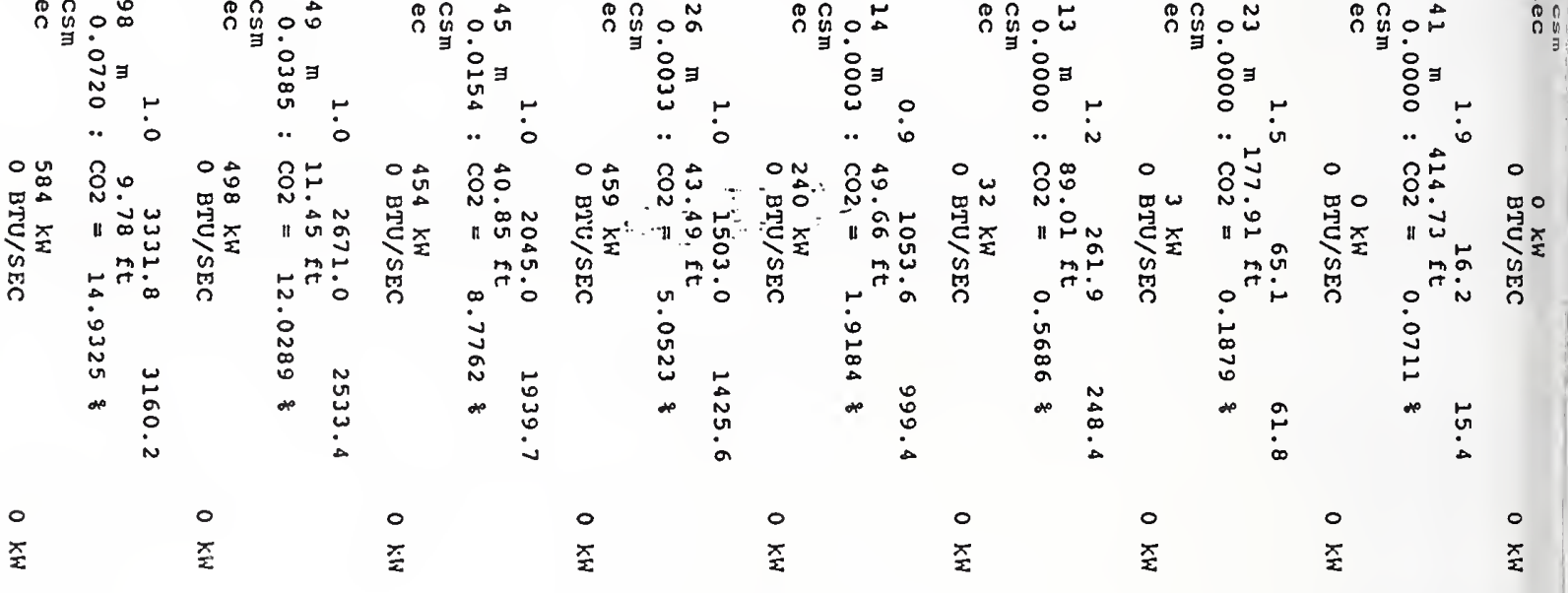
$\therefore$ :

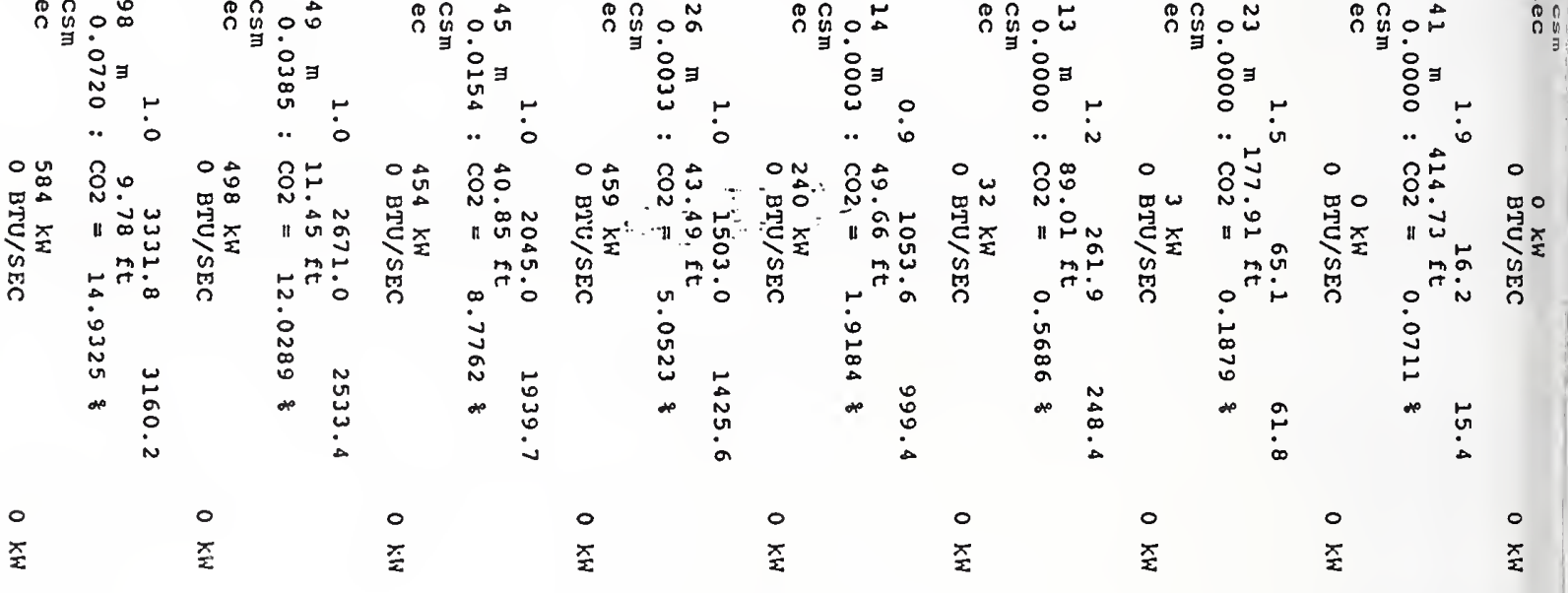
$\AA^{3}$
. 0 . $\quad . \quad$ io

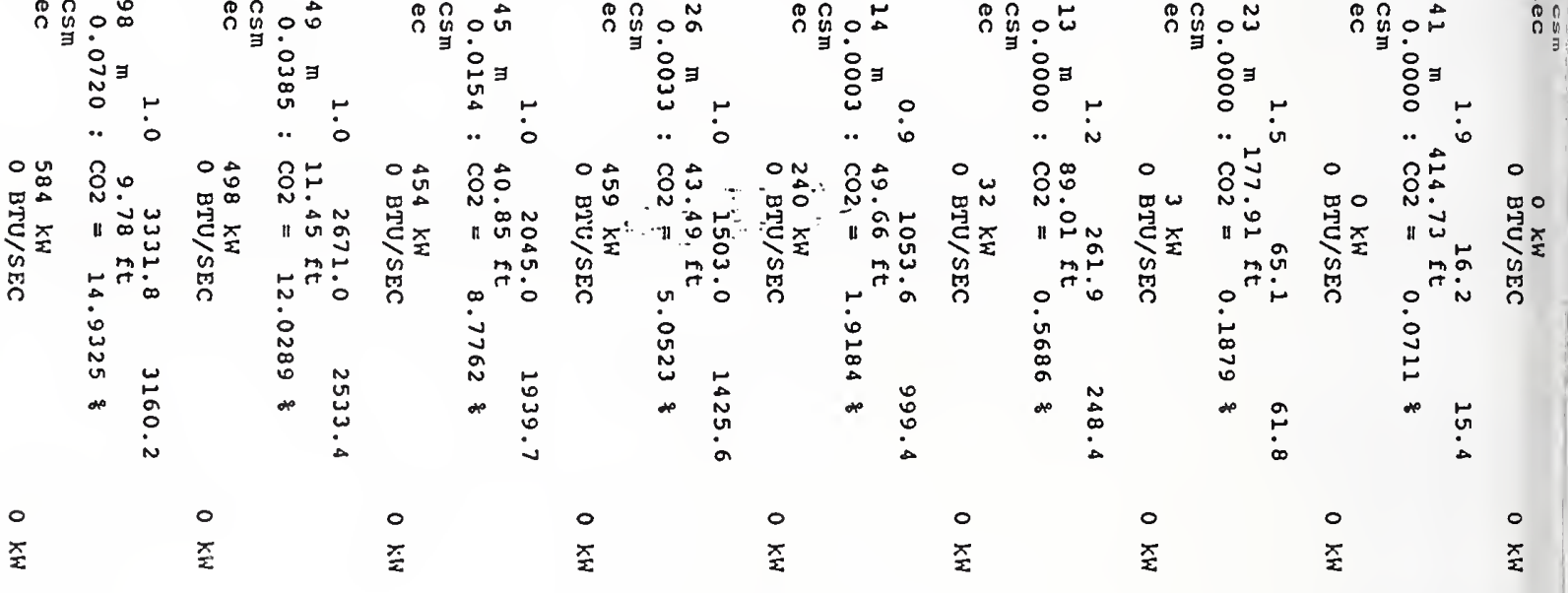
$:^{\exists}$

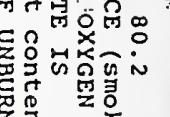

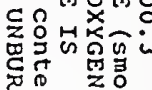

突导 11 宔

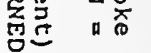

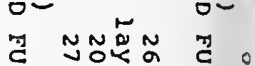

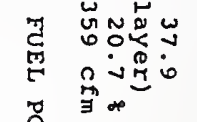

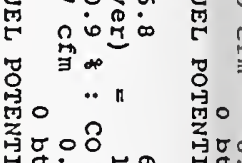

wo

उoo

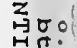

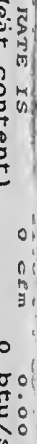

.

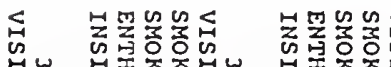

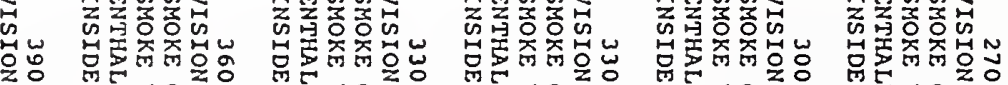

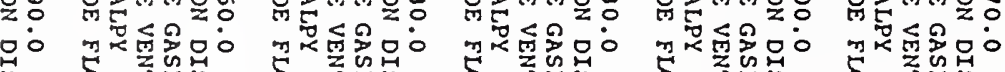

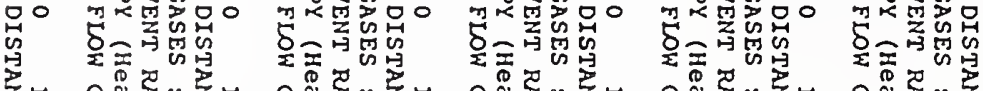

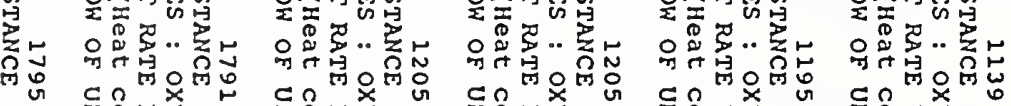

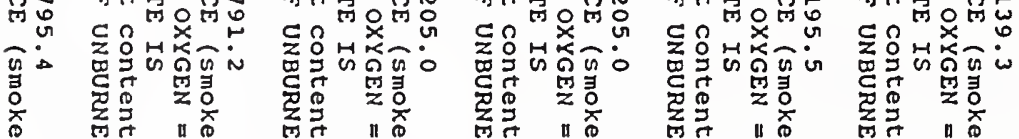

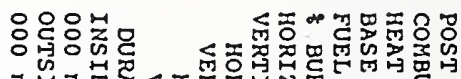

只 กำ

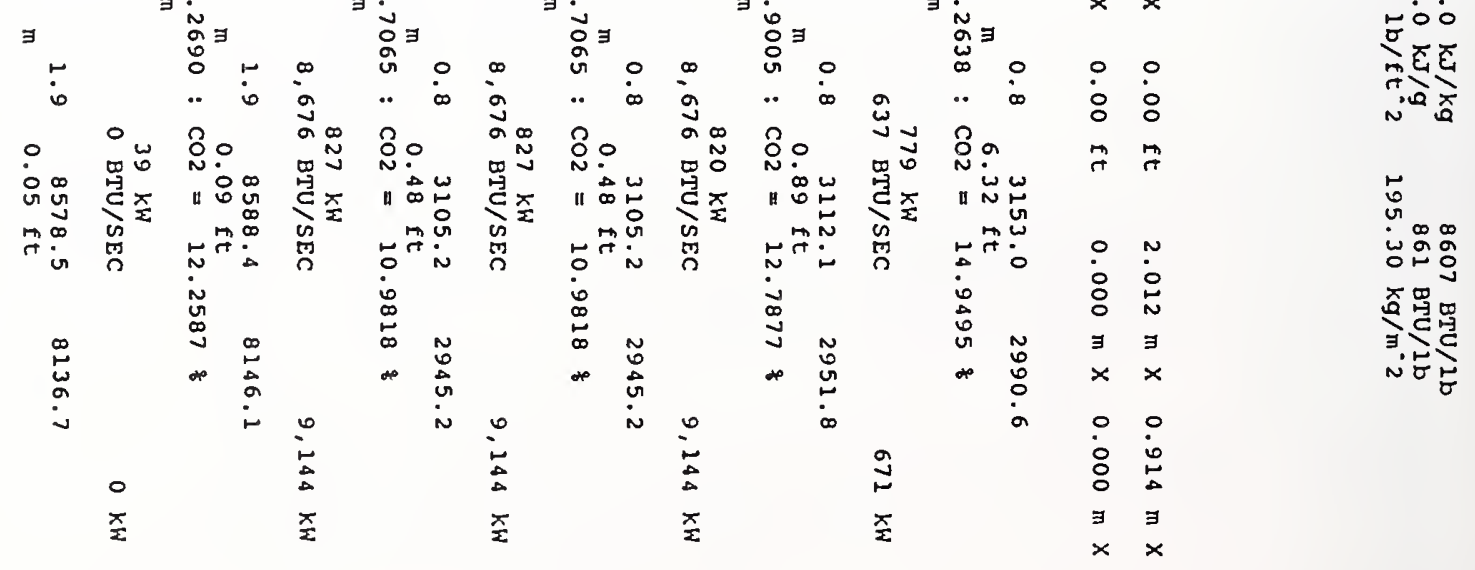


APPENDIX B

Printout of results of FIRE SIMULATOR run for the ABMC suite.

This run considers the suite as a closed space until 270 seconds, at which time it assumes that both of the suite doors are opened.
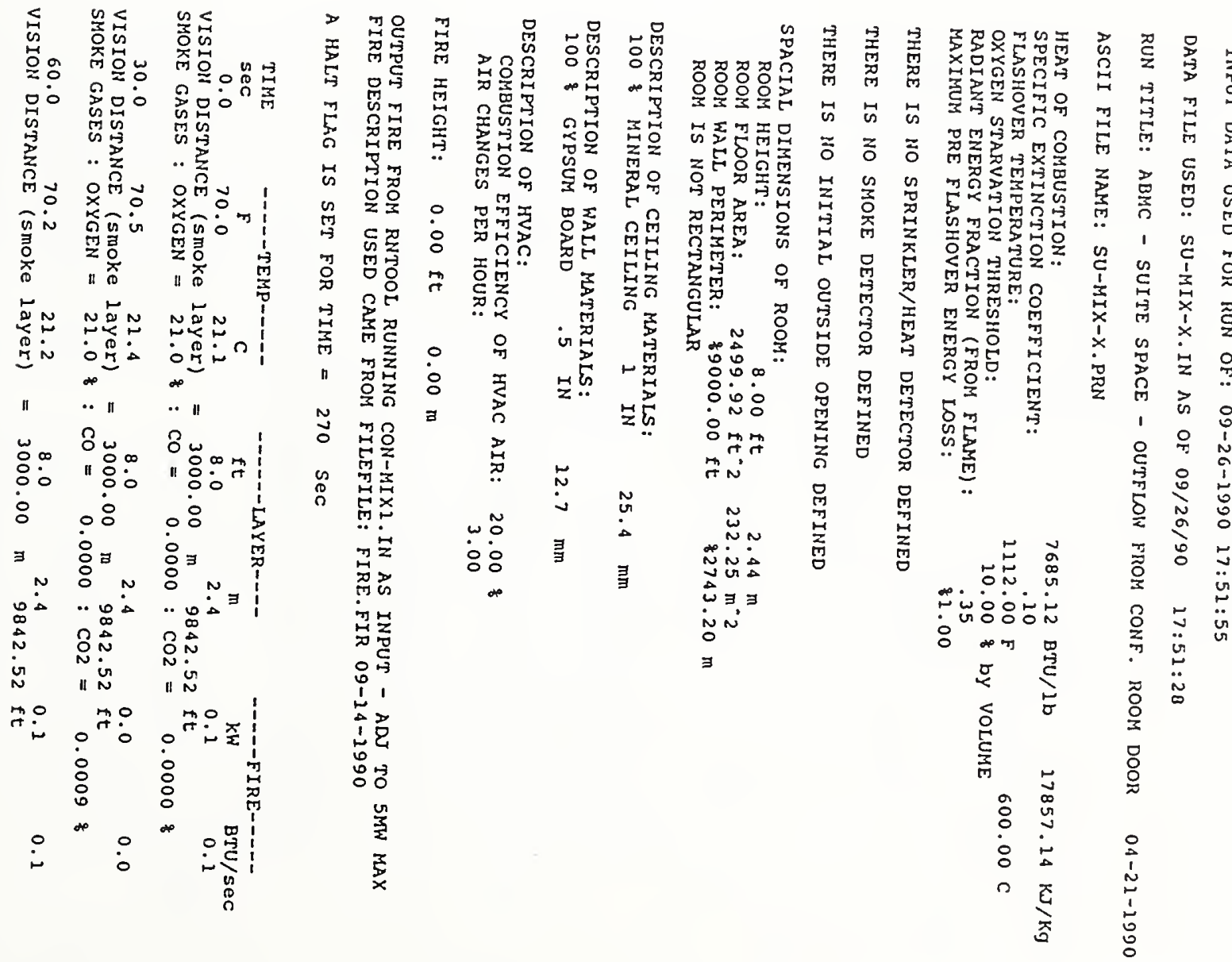


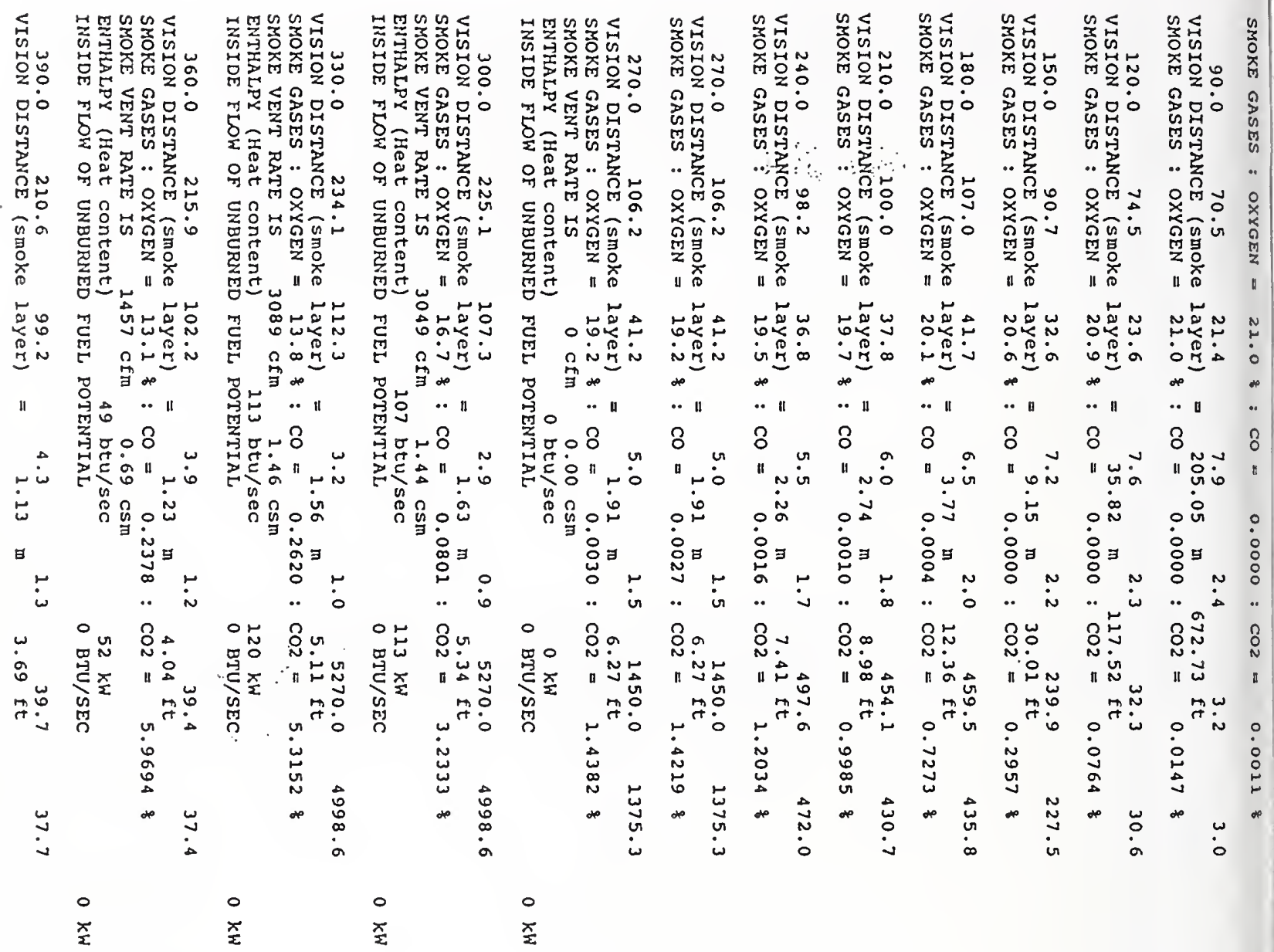

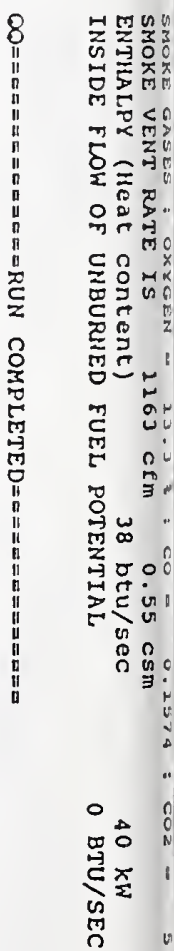


APPENDIX C

Printout of results of FIRE SIMULATOR run for 5th floor

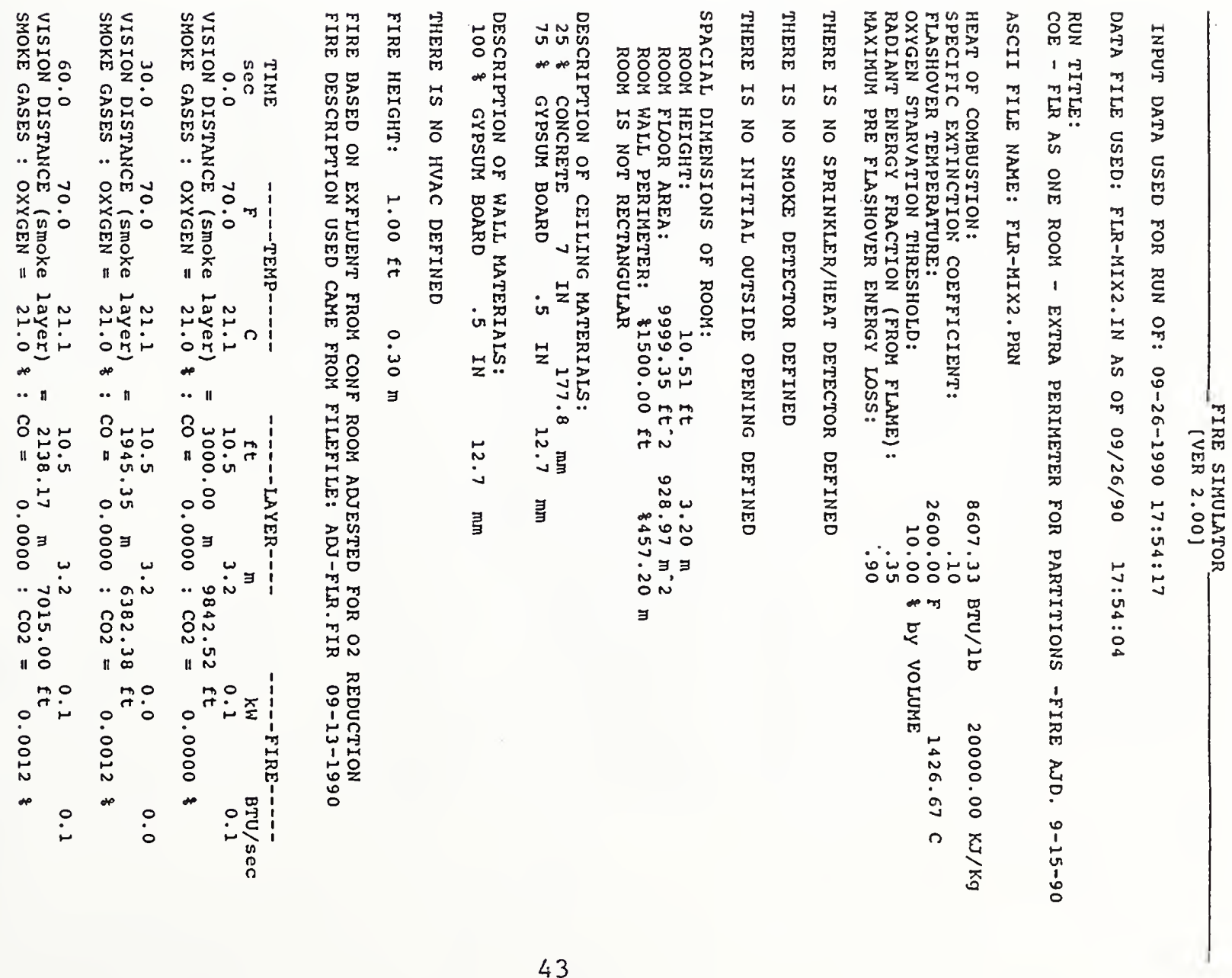




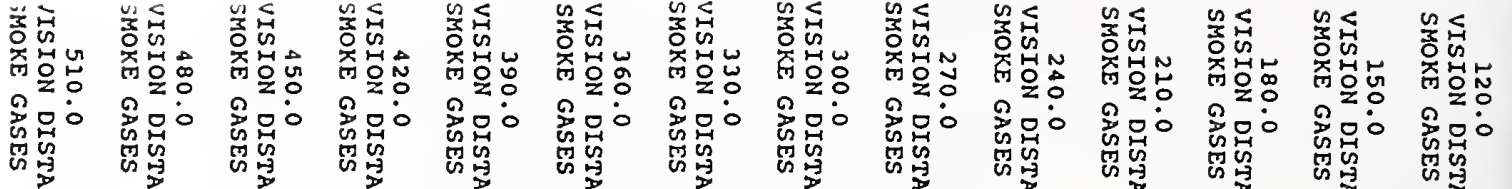

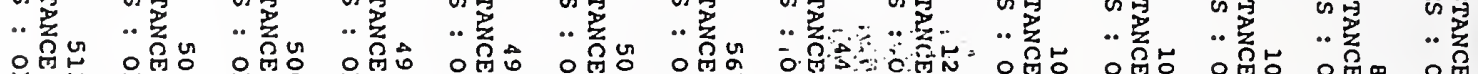

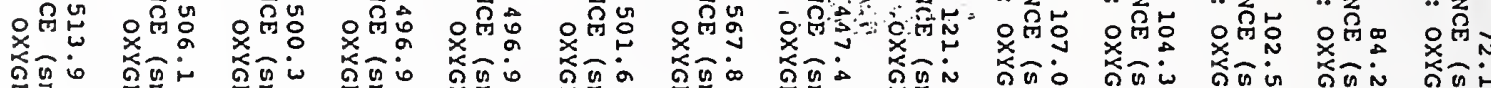

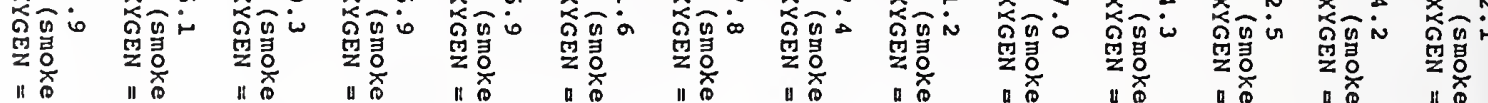

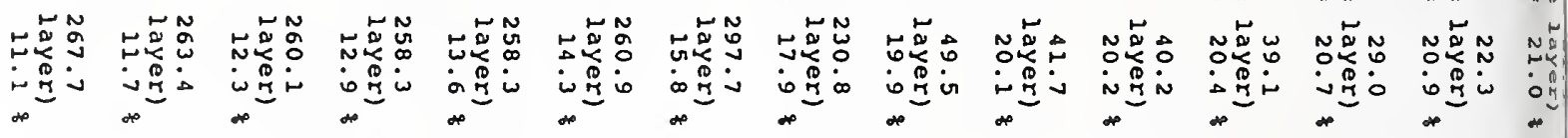

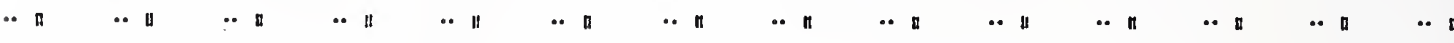

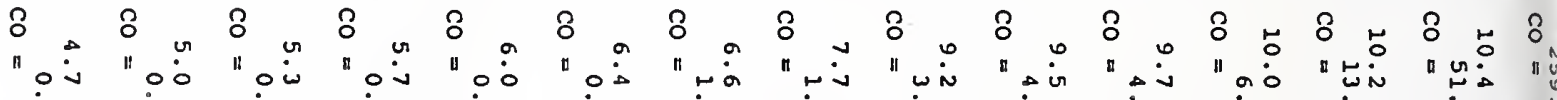

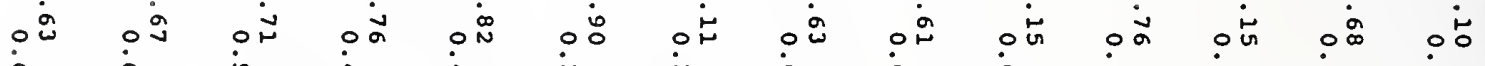

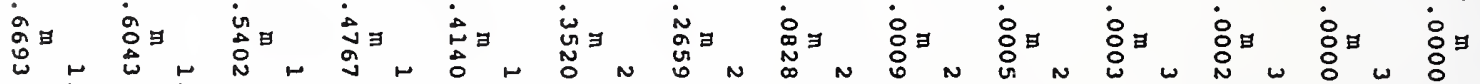

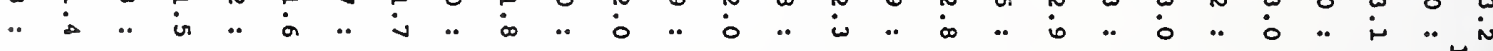

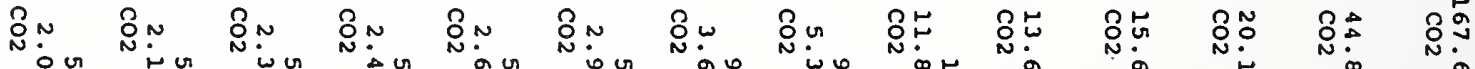

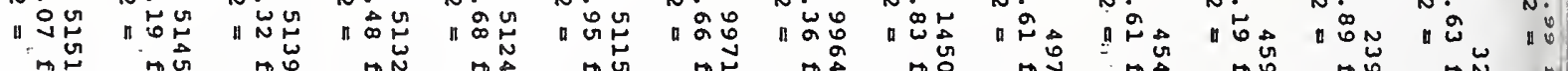

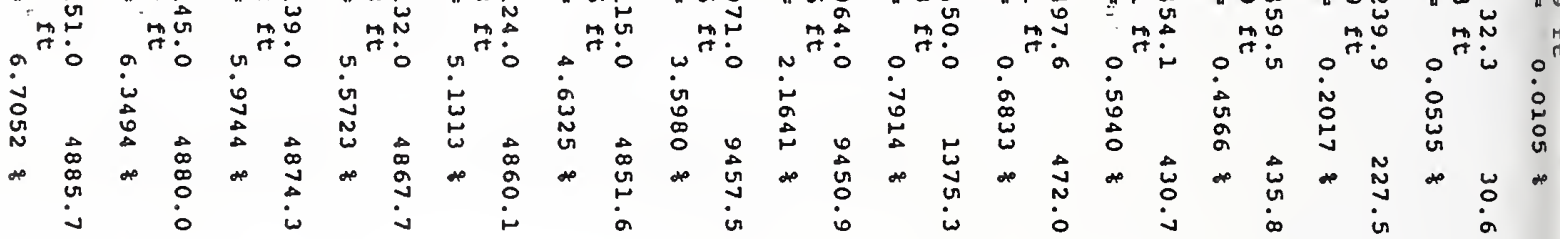

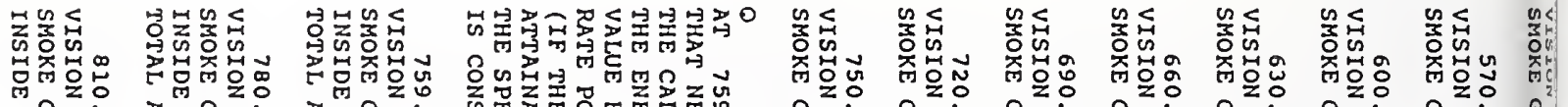

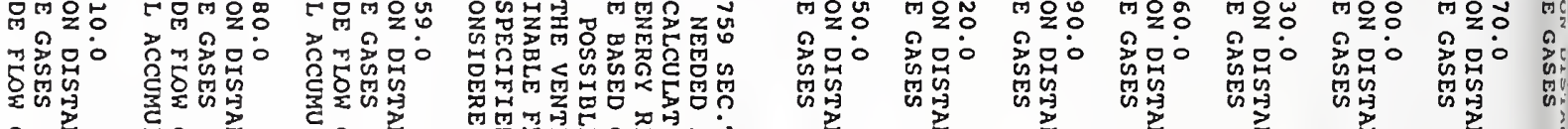

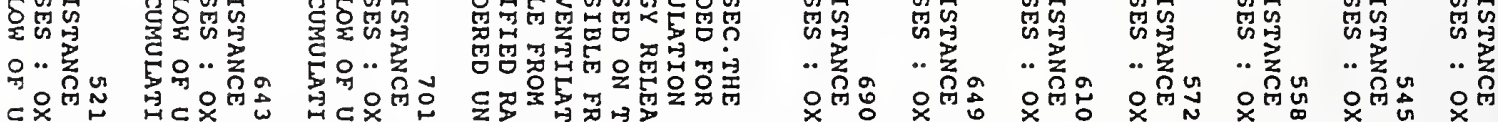

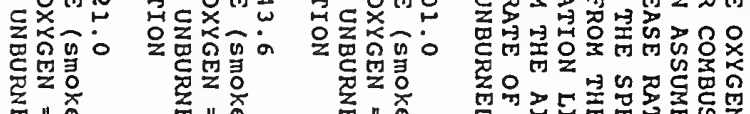

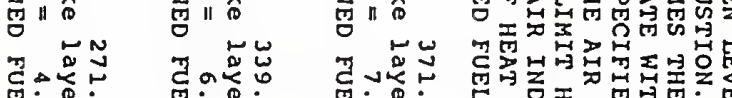

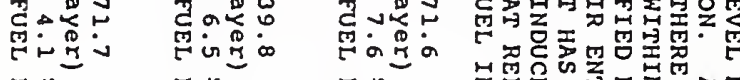

"0 苞。 N

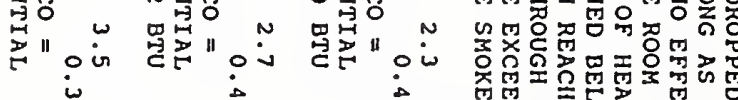

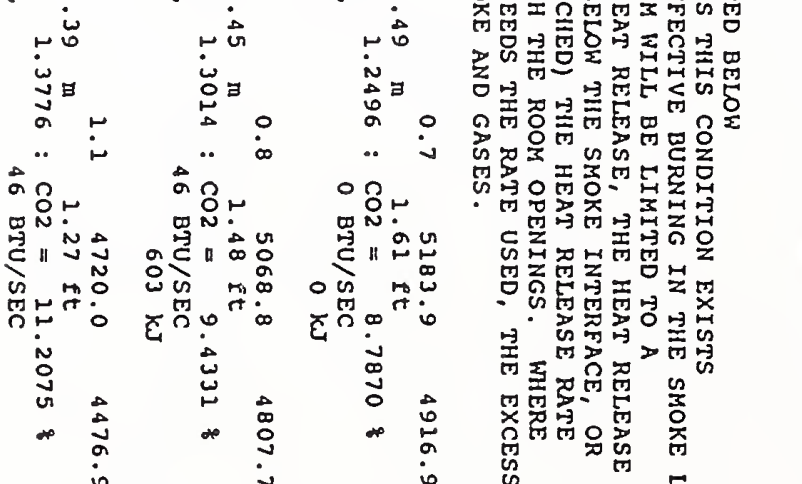

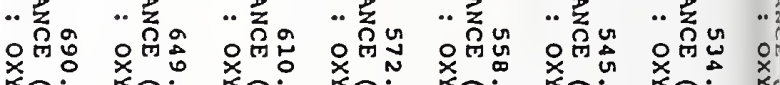

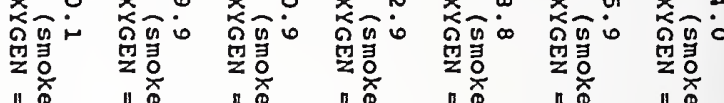

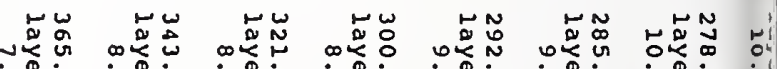

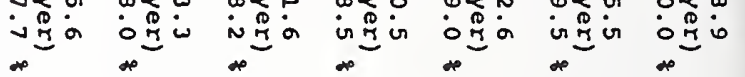
..

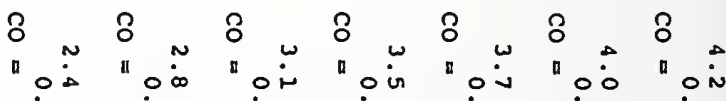

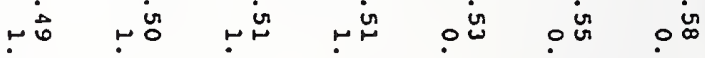

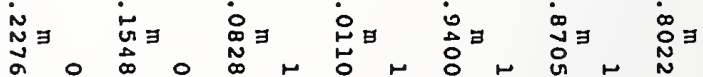

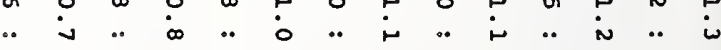

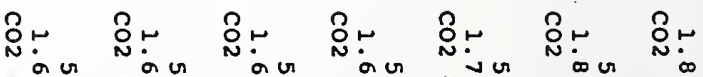
"

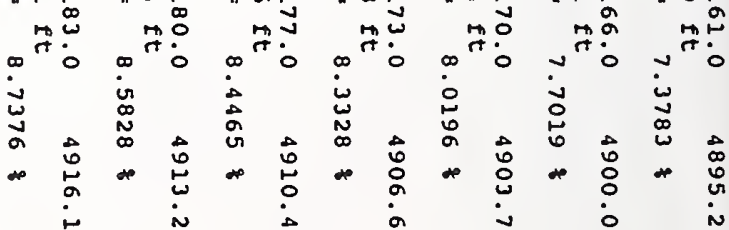




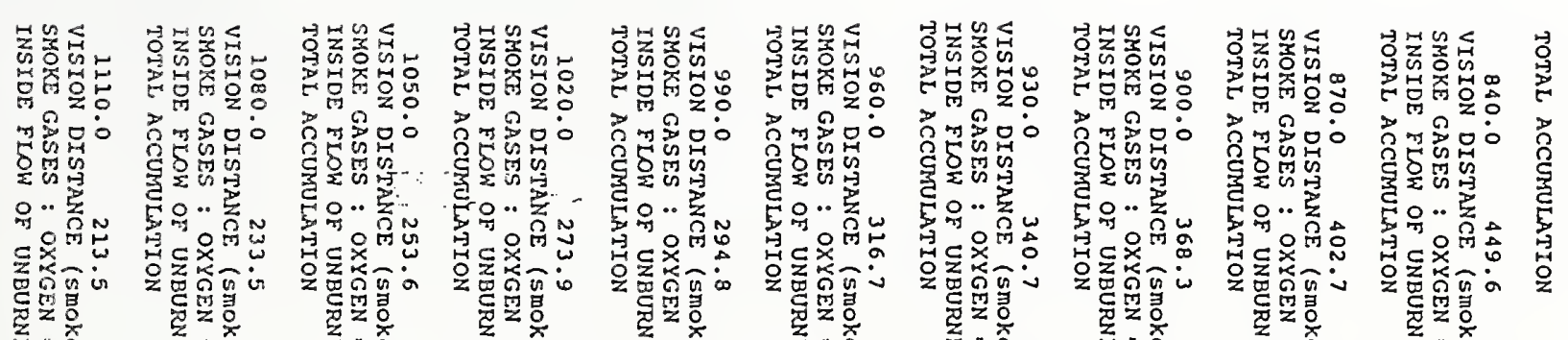

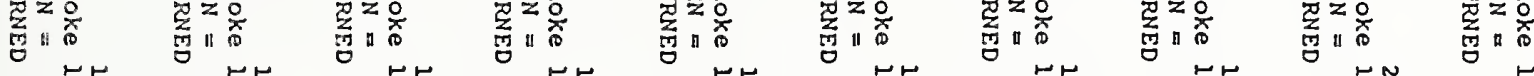

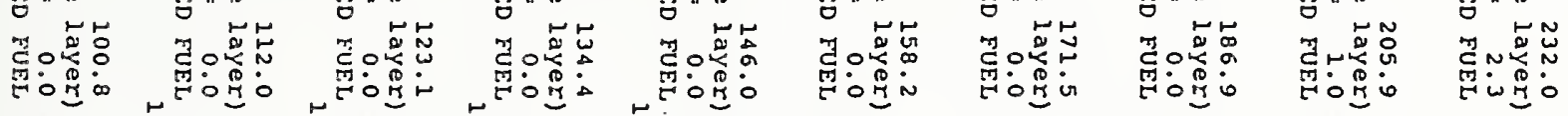

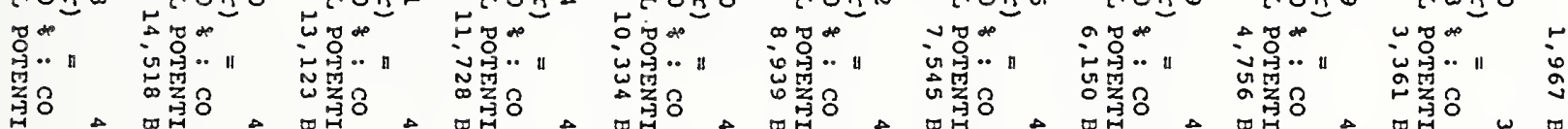

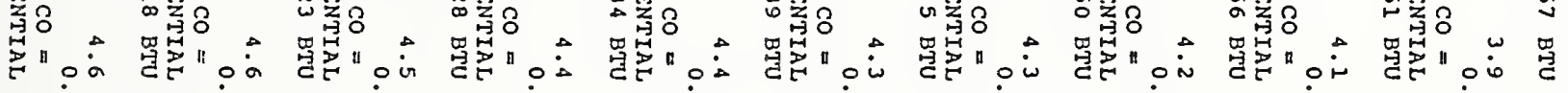

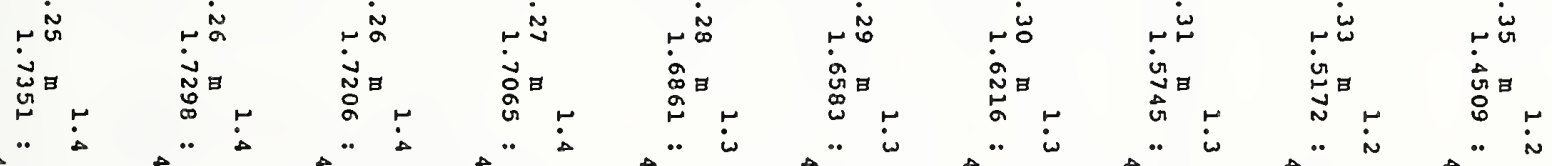

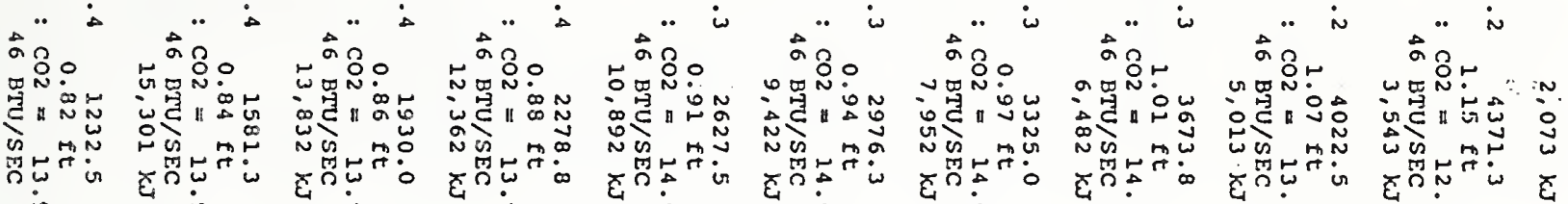

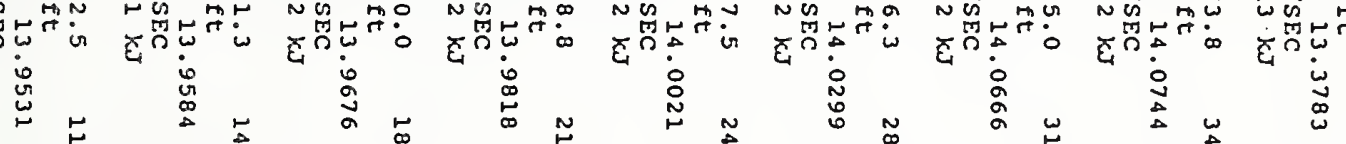

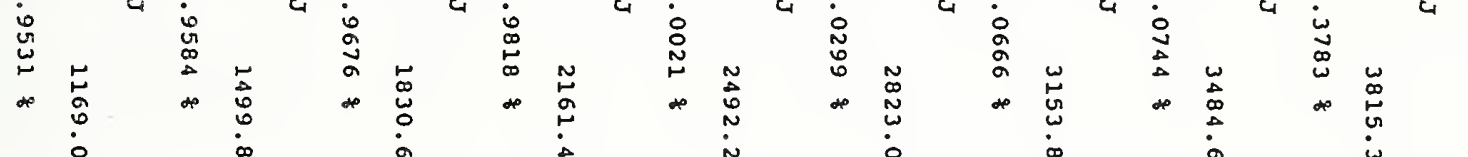

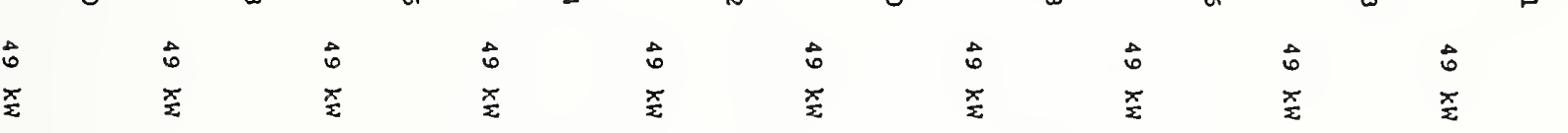

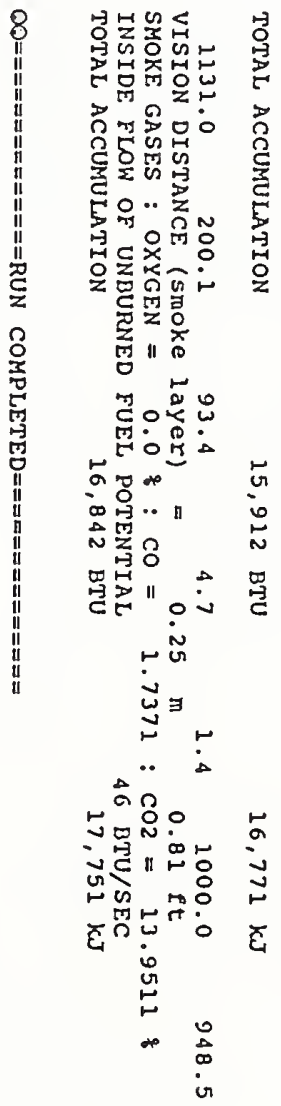


APPENDIX D

Printout of results of FIRE SIMULATOR runs used to estimate the response of sprinklers and smoke detectors.

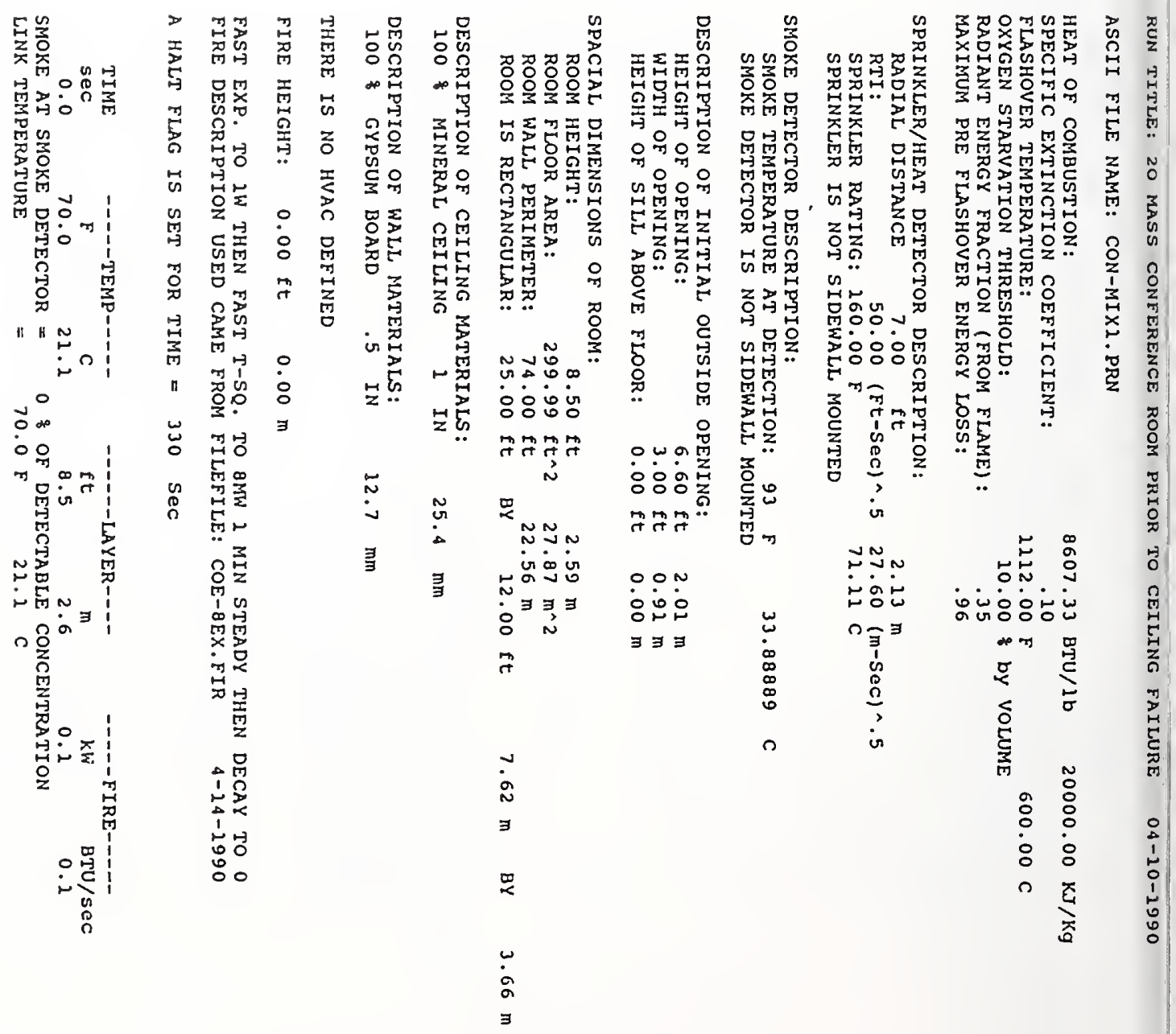




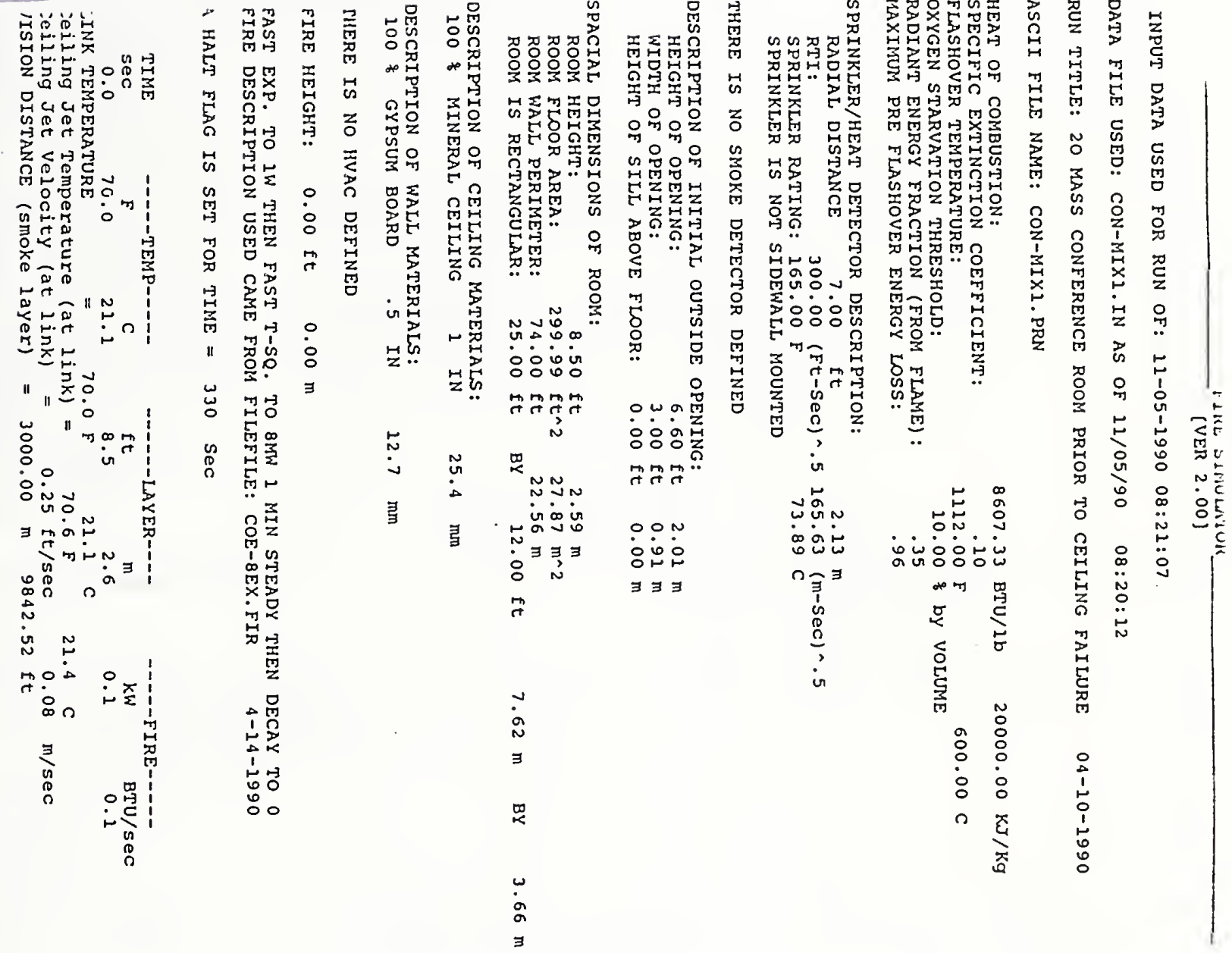

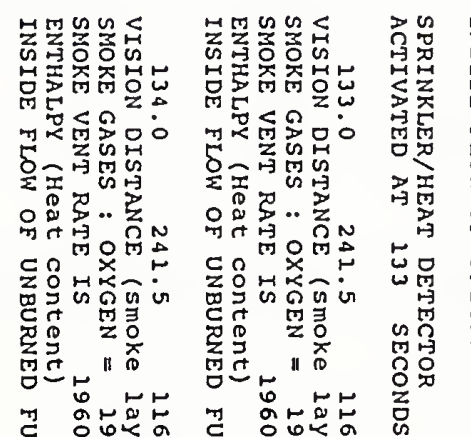

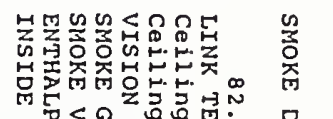

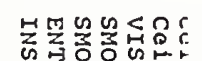

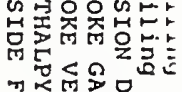

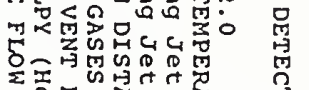

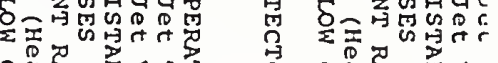

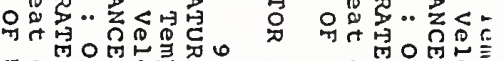

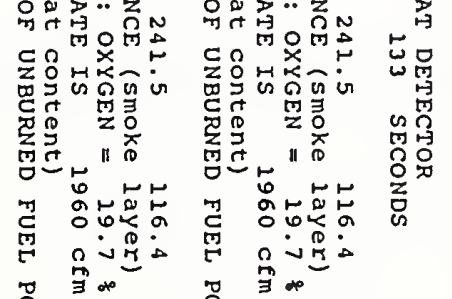

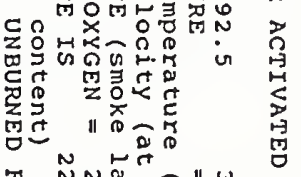

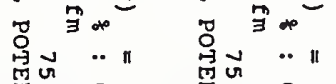

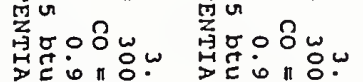

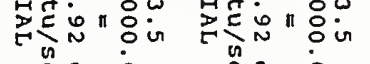

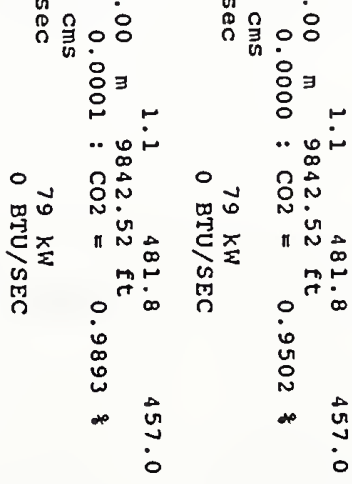

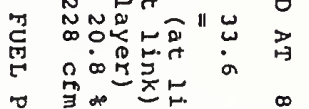

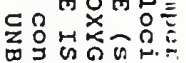

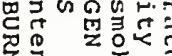

骨然

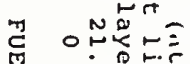

Mํ.

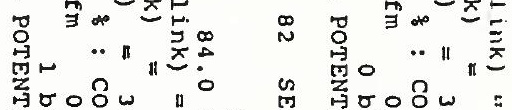

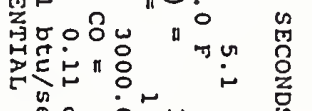

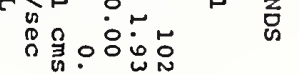

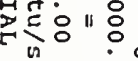

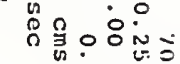
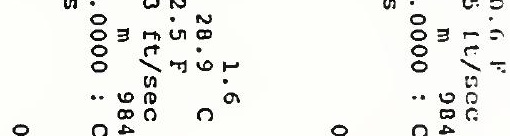

俚

궁ำ
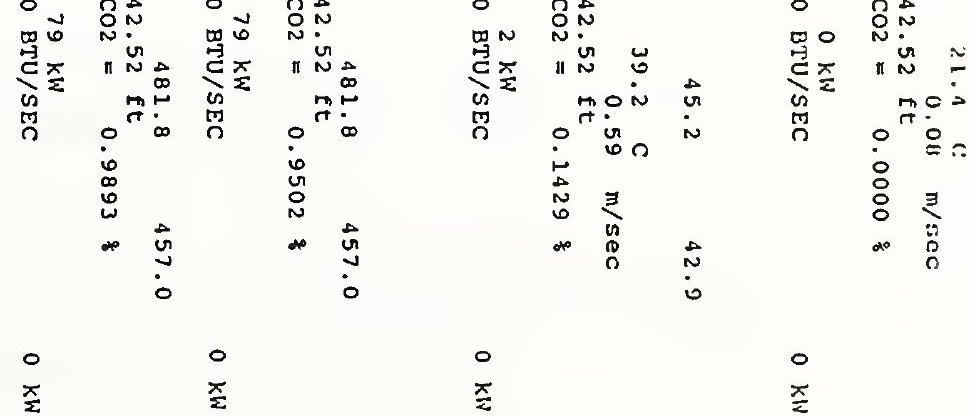

줄

x 


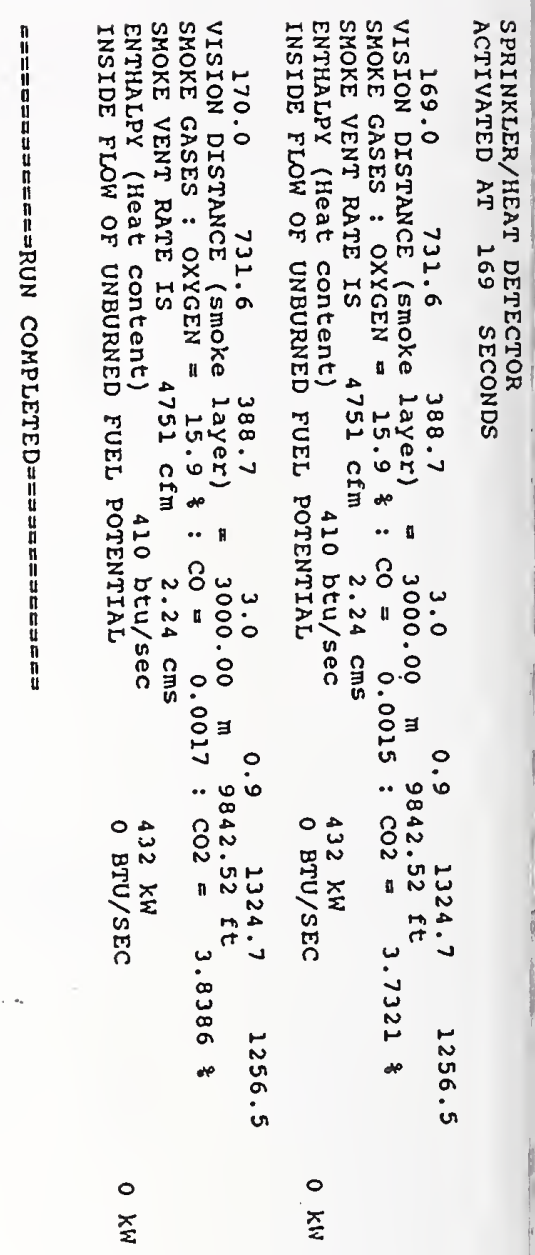




\begin{tabular}{|c|c|c|c|}
\hline \multirow{2}{*}{$\begin{array}{c}\text { U.S. DEPARTMENT OF COMMERCE } \\
\text { NATIONAL INSTITUTE OF STANDARDS AND TECHNOLOGY }\end{array}$} & \multicolumn{3}{|c|}{ (ERB USE ONLY) } \\
\hline & \multicolumn{2}{|c|}{ ERB CONTROL NUMBER } & \multirow[t]{2}{*}{ DIVISION } \\
\hline & & & \\
\hline MANUSCRIPT REVIEW AND APPROVAL & $\begin{array}{l}\text { PUBLCATION REPORT } \\
\text { NISTIR } 4489\end{array}$ & BER & CATEGORY CODE \\
\hline $\begin{array}{l}\text { JCTIONS: ATTACH ORIGINAL OF THIS FORM TO ONE (1) COPY OF MANUSCRIPT AND SEND TO } \\
\text { ECRETARY, APPROPRIATE EDITORIAL REVIEW BOARD. }\end{array}$ & $\begin{array}{l}\text { PUBUCATION DATE } \\
\text { June } 1994\end{array}$ & NUW & BER PRINTED PAGES \\
\hline
\end{tabular}
AND SUBTITLE (CITE IN FULL)

ire Growth Analysis of the Fire of March 20, 1990, Pulaski Building, 20 Massachusetts venue, N.W., Washington, DC

IACT OR GRANT NUMBER TYPE OF REPORT AND/OR PERIOD COVERED

R(S) (LAST NAME, FIRST INITIAL, SECOND INITIAL)

arold E. Nelson

ATORY AND DIVISION NAMES (FIRST NIST AUTHOR ONLY)

1ilding and Fire Research Laboratory

ORING ORGAMIZATION NAME AND COMPLETE ADDRESS (STREET, CITY, STATE, ZIP)

.S. Department of the Army

Corps of Engineers

SED FOR NIST PUBUCATION

JOURNAL OF RESEARCH (NIST JRES)

J. PHYS. \& CHEM. REF. DATA (JPCRD)

HANDBOOK (NIST HB)

SPECIAL PUBUCATION (NIST SP)

TECHNICAL NOTE (NIST TN)

SED FOR NON-NIST PUBLCATION (CITE FULLY

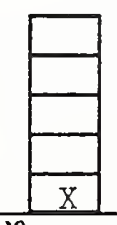

MONOGRAPH (NIST MN)

NATL. STD. REF. DATA SERIES (NIST NSRDS)

FEDERAL INF. PROCESS. STDS. (NIST FIPS)

UST OF PUBUCATIONS (NIST LP)

NIST INTERAGENCY/INTERMAL REPORT (NISTIR)

PERFORMING ORGANIZATION (CH
\begin{tabular}{|l|l}
\hline & $\begin{array}{l}\text { NIST/GAITHERSBURG } \\
\text { NIST/BOULDER } \\
\text { JILA/BOULDER }\end{array}$
\end{tabular}

JILA/BOULDER

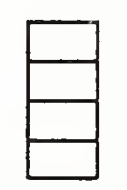

LETTER CIRCULAR BUILDING SCIENCE SERIES PRODUCT STANDARDS OTHER

PUBUSHING MEDIUM

PAPER

DISKETTE (SPECIFY) OTHER (SPECIFY)

ACT (A 2000-CHARACTER OR LESS FACTUAL SUMMARY OF MOST SIGNIFICANT INFORMATION. IF DOCUMENT INCLUDES A SIGNIFICANT BIBUOGRAPHY ERATURE SURVEY, CITE IT HERE. SPELL OUT ACRONYMS ON FIRST REFERENCE.) (CONTINUE ON SEPARATE PAGE, IF NECESSARY.)

analysis of an office building fire was made using fire modeling techniques. The data conduct the analysis was obtained through on-site inspection and interviews. The alysis describes a rapid fire developing in easily ignited boxing materials that ashed over in about six minutes from flame initiation, causing failure of the ceiling stem, venting of fire products in the plenum system above the ceiling, and rapid filling the entire flow area with smoke. The report suggests a likely source of ignition I provides analysis of the impact that several fire protection systems would have 1 were they present at the time of this fire.

JRDS (MAXIMUM OF 9; 28 CHARACTERS AND SPACES EACH; SEPARATE WITH SEMICOLONS; ALPHABETIC ORDER; CAPITALIZE ONLY PROPER NAMES) .re investigation; fire modeling; fire spread; flashover; office building

$\overline{\text { BIUTY }}$

UNUMITED ORDER FROM SUPERINTENDENT OF DOCUMENTS, U.S. GPO, WASHIOTON, DC ZOAO ORDER FROM SUPERINTENDENT OF DOCUMENTS, U.S. GPO, WASHINGTON, DC 20402 ORDER FROM NTIS, SPRIMGFIELD, VA 22161
NOTE TO AUTHOR(S): IF YOU DO NOT WISH THIS MANUSCRIPT ANNOUNCED BEFORE PUBUCATION, PLEASE CHECK HERE. 


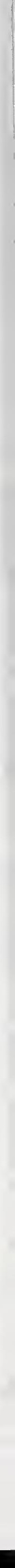





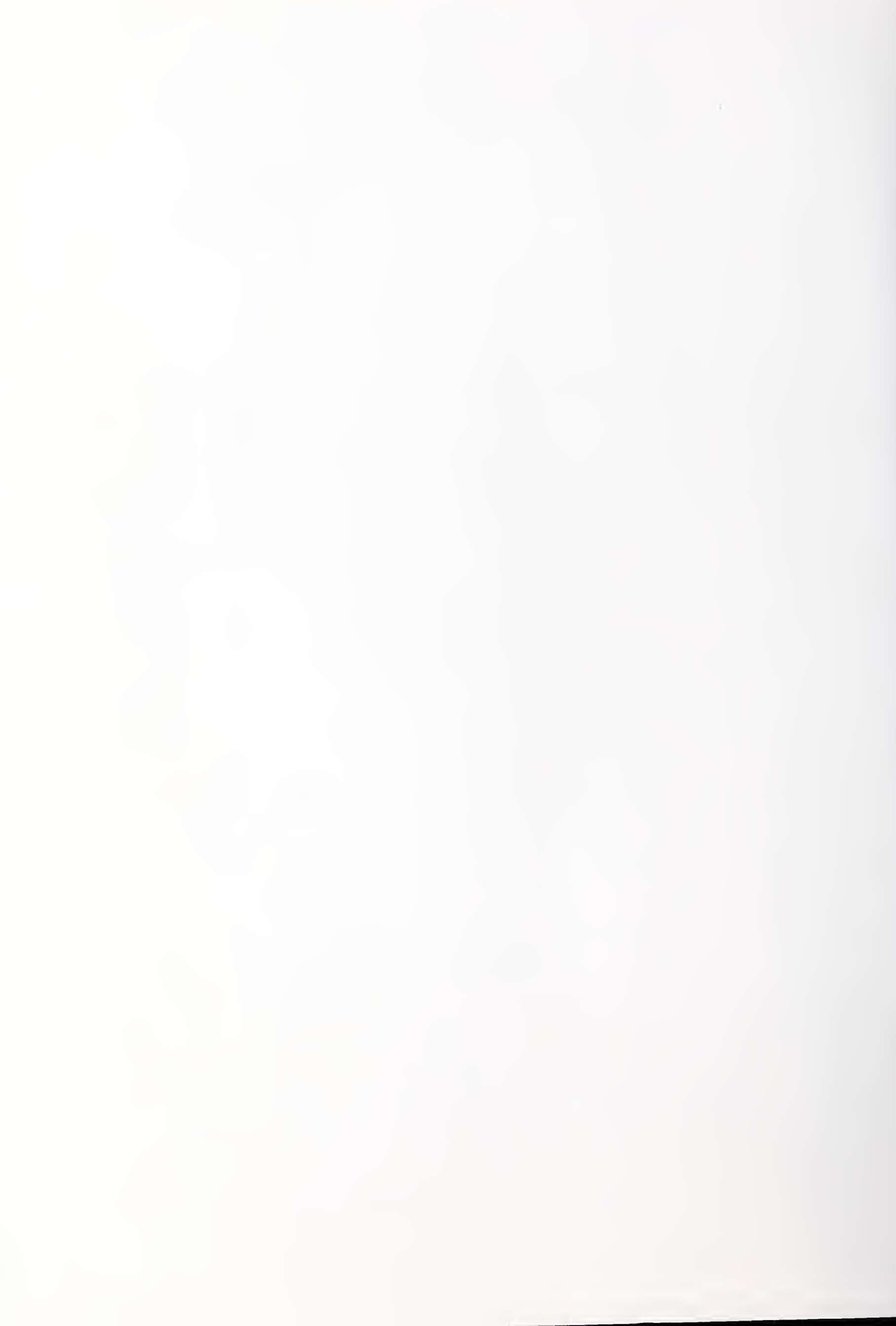

